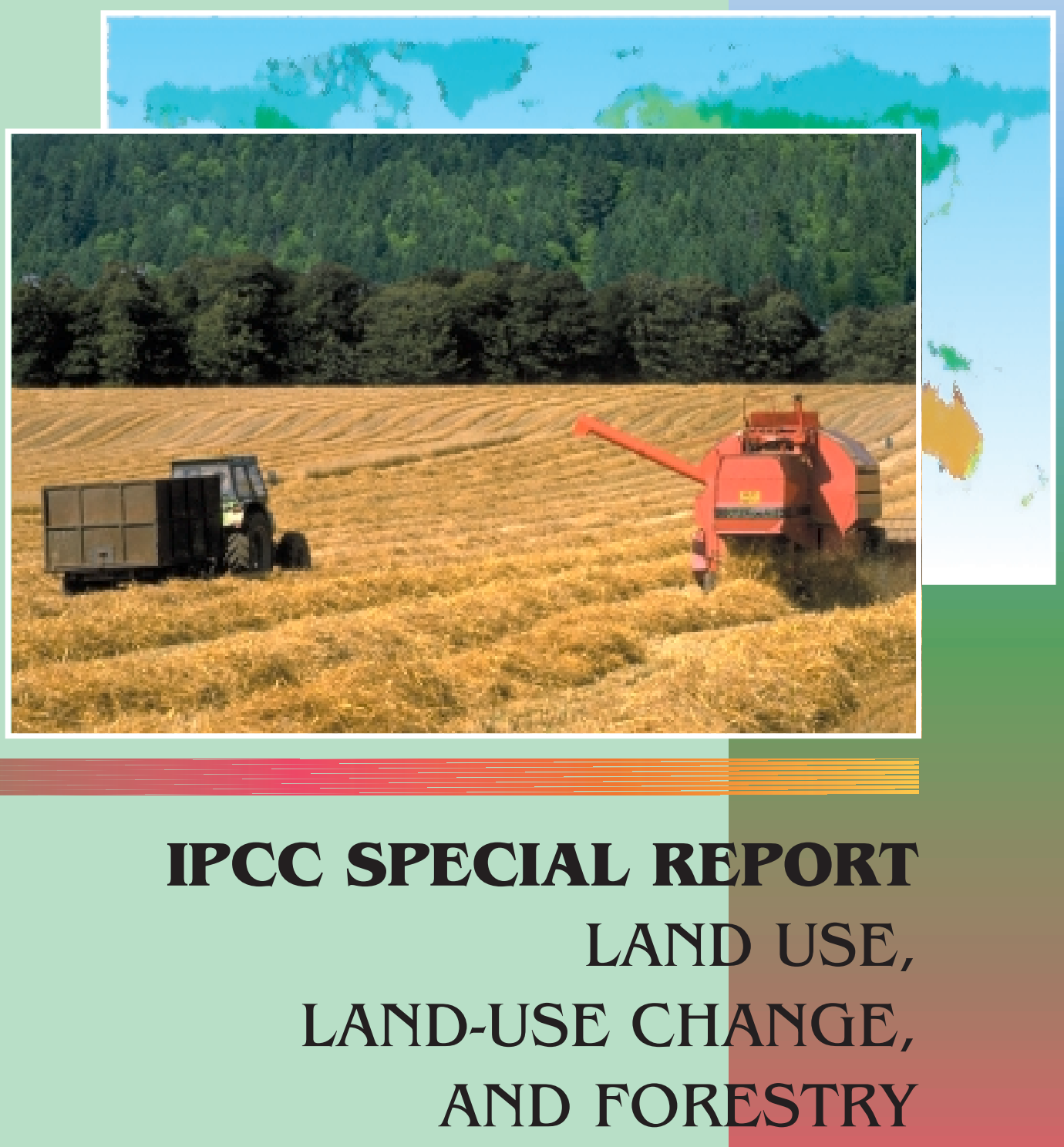

Summary for Policymakers 


\title{
INTERGOVERNMENTAL PANEL ON CLIMATE CHANGE
}

WMO

UNEP

\author{
Summary for Policymakers
}

\author{
Land Use, \\ Land-Use Change, \\ and Forestry
}

A Special Report of the Intergovernmental Panel on Climate Change 
(C) 2000, Intergovernmental Panel on Climate Change

ISBN: 92-9169-114-3 


\section{Contents}

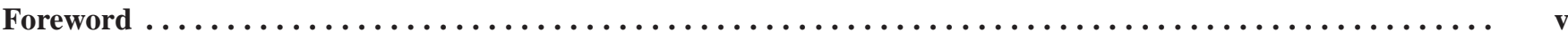

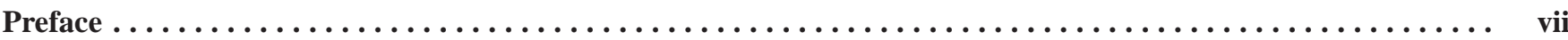

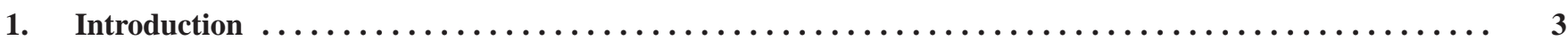

Part I

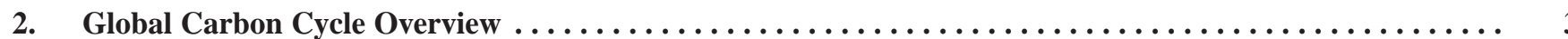

\section{Part II}

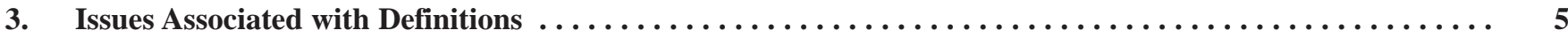

3.1 Forests, Afforestation, Reforestration, and Deforestation $\ldots \ldots \ldots \ldots$

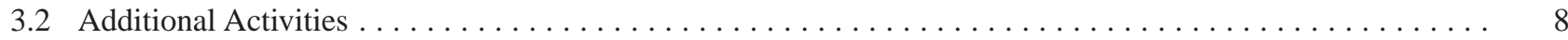

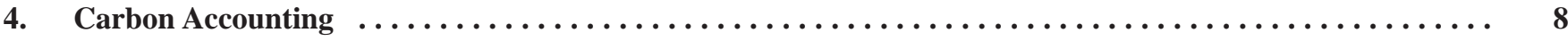

\section{Part III}

5. Methods for Measuring and Monitoring $\ldots \ldots \ldots \ldots \ldots \ldots \ldots \ldots$

6. Estimates of Average Annual Carbon Stock Changes/Accounted for ARD Activities

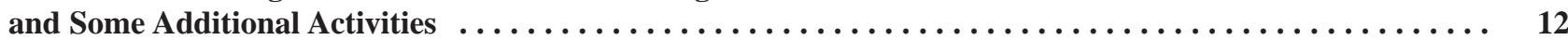

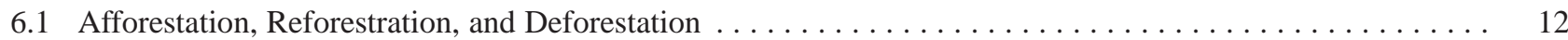

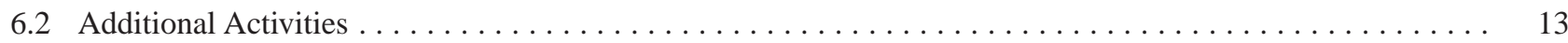

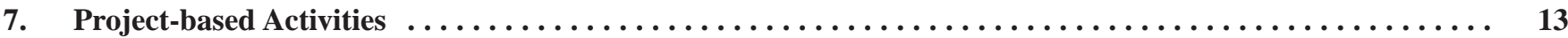

8. Reporting Guidelines for the Relevant Articles of the Kyoto Protocol .................... 16

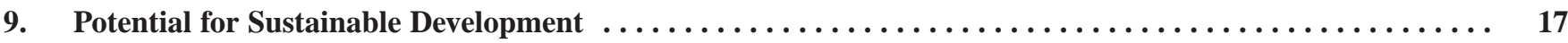

\section{Appendices}

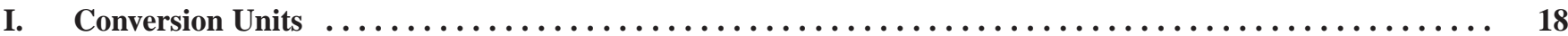

II. Relevant Portions of Kyoto Protocol Articles Discussed in this Special Report . . . . . . . . . . . . . 19

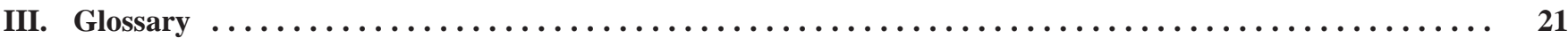

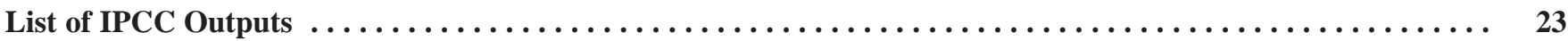




\section{Foreword}

The Intergovernmental Panel on Climate Change (IPCC) was jointly established by the World Meteorological Organization (WMO) and the United Nations Environment Programme (UNEP) in 1988 to: (i) assess available information on the science, the impacts, and the economics of, and the options for mitigating and/or adapting to, climate change; and (ii) provide, on request, scientific/technical/socioeconomic advice to the Conference of the Parties (COP) to the United Nations Framework Convention on Climate Change (UNFCCC). Since then, the IPCC has produced a series of Assessment Reports, Special Reports, Technical Papers, methodologies, and other products that have become standard works of reference, widely used by policymakers, scientists, and other experts.

The Special Report on Land Use, Land-Use Change, and Forestry was prepared in response to a request from the United Nations Framework Convention on Climate Change (UNFCCC) Subsidiary Body for Scientific and Technological Advice (SBSTA). At its Eighth Session in Bonn on 2-12 June 1998, SBSTA requested a report examining the scientific and technical state of understanding for carbon sequestration strategies related to land use, land-use change, and forestry activities and relevant Articles of the Kyoto Protocol. The scope, structure, and outline of the Special Report was approved by the IPCC in plenary meetings during its Fourteenth Session in Vienna, Austria, from 1-3 October 1998.

This Special Report discusses the global carbon cycle and how different land use and forestry activities currently affect standing carbon stocks and emissions of greenhouse gases. It also looks forward and examines future carbon uptake and emissions that may result from employing varying definitional scenarios and carbon accounting strategies, linked to the Kyoto Protocol, within the forestry and land-use sectors.

As is usual in the IPCC, success in producing this document has depended on the enthusiasm and cooperation of volunteers dispersed worldwide who give freely of their professional and personal time. We would like to express our gratitude to all the Coordinating Lead Authors, Lead Authors, Contributing Authors, Review Editors, and Expert Reviewers. These individuals have expended considerable effort to produce this report and we are extremely grateful for their commitment to the IPCC process.

We would also like to express our sincere thanks to:

- Robert T. Watson - the Chairman of the IPCC and Chair of this Special Report

- Ian Noble, Bert Bolin, and N. H. Ravindranath-the Coordinators of this Special Report

- Neal Leary, Osvaldo Canziani, and Martin Manning (Working Group II); David Griggs, Fortunat Joos, and John Stone (Working Group I); and Bert Metz, Eduardo Calvo, and Peter Kuikman (Working Group III) - the Science Steering Committee for this Special Report

- David J. Verardo and the staff of the Working Group II Technical Support Unit

- N. Sundararaman - the Secretary of the IPCC, and the Secretariat staff.

\section{G.O.P. Obasi}

Secretary-General

World Meteorological Organization

\section{K. Töpfer}

Executive Director

United Nations Environment Programme

and

Director-General

United Nations Office in Nairobi 


\section{Preface}

The Intergovernmental Panel on Climate Change (IPCC) Special Report on Land Use, Land-Use Change, and Forestry (SR-LULUCF) has been prepared in response to a request from the United Nations Framework Convention on Climate Change (UNFCCC) Subsidiary Body for Scientific and Technological Advice (SBSTA). At its eighth session in Bonn, Germany, 2-12 June 1998, the SBSTA requested a report examining the scientific and technical implications of carbon sequestration strategies related to land use, land-use change, and forestry activities. The scope, structure, and outline of this Special Report was approved by the IPCC in plenary meetings during its Fourteenth Session.

This Special Report examines several key questions relating to the exchange of carbon between the atmosphere and the terrestrial pool of aboveground biomass, below-ground biomass, and soils. Vegetation exchanges carbon dioxide between the atmosphere and the terrestrial biosphere through photosynthesis and plant and soil respiration. This natural exchange has been occurring for hundreds of millions of years. Humans are changing the natural rate of exchange of carbon between the atmosphere and the terrestrial biosphere through land use, land-use change, and forestry activities. Consequently, it is important to examine how carbon flows between different pools and how carbon stocks change in response to afforestation, reforestation, and deforestation (ARD) and other land-use activities.

The aim of the SR-LULUCF is to assist the Parties to the Kyoto Protocol by providing relevant scientific and technical information to describe how the global carbon cycle operates and what the broad-scale opportunities and implications of ARD and additional human-induced activities are, now and in the future. This Special Report also identifies questions that Parties to the Protocol may wish to consider regarding definitions and accounting rules.

This Special Report should be helpful in the implementation of relevant Articles in the Kyoto Protocol by providing information about measurement and monitoring techniques for assessing changes in carbon stocks in Annex I and non-Annex I countries, the applicability of the Revised 1996 IPCC Guidelines for National Greenhouse Gas Inventories for national and project-level accounting, the implications of Articles 3.3 and 3.4, and project activities relating to sustainable development.

This Special Report also estimates potential carbon yields from ARD and additional activities by evaluating changes in carbon stocks for different ecosystems, current land area converted per

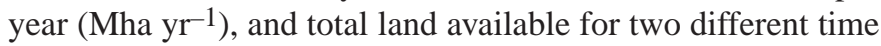
periods: near term (between now and the end of the first commitment period) and longer term (1990-2040). Project experience is also provided for several projects, primarily in tropical countries.

Implementation of the Kyoto Protocol requires mutually acceptable definitions for a wide range of terms to ensure that effective sequestration strategies are planned and implemented. For instance, if key terms such as forests, afforestation, reforestation, and deforestation are not clearly defined or if carbon accounting principles are not clearly established, it becomes difficult to comprehend the implications of different land-use activities. Hence, the challenge is to derive a set of definitions that are simple and consistent with the aims of the UNFCCC and the Kyoto Protocol. To achieve this goal, definitions should be applicable to all Parties and be addressed using data that can be readily accessed. This process will enable Parties to estimate carbon stock changes that would need to be included in the calculation of assigned amounts.

In examining issues relating to land use, land-use change, and forestry, several critical scientific and technical questions present themselves. What are the implications of using different definitions or sets of definitions? Do the definitions need to be flexible enough to accommodate our present understanding of carbon dynamics while allowing for future innovations and advances? How do we distinguish among direct humaninduced activities, indirect human-induced activities, and natural environmental variability that affects carbon uptake and release? How do we differentiate between pre- and post-1990 direct human activities? How do we measure changes in carbon stocks and flows in a transparent and verifiable manner over time? How permanent are carbon stocks? To what extent do we trade simplicity for accuracy in accounting?

In summary, the SR-LULUCF is written with a variety of questions in mind that examine the scientific and technical aspects of carbon sequestration in agricultural and forestry sectors as well as the implications of land use, land-use change, and forestry activities on environmental and socioeconomic issues, conservation, and sustainable resource management and development issues.

\section{Robert T. Watson and David J. Verardo}




\section{Summary For Policymakers}

\section{LAND Use, LAND-Use Change, AND Forestry}

\section{A Special Report of the Intergovernmental Panel on Climate Change}

This summary, approved in detail at IPCC Plenary XVI (Montreal, Canada, 1-8 May 2000), represents the formally agreed statement of the IPCC concerning current understanding of land use, land-use change, and forestry activities and their relationship to the Kyoto Protocol.

Based on a draft prepared by:

Robert Watson (USA), Ian Noble (Australia), Bert Bolin (Sweden), N.H. Ravindranath (India), David Verardo (USA), Ken Andrasko (USA), Michael Apps (Canada), Sandra Brown (USA), Graham Farquhar (Australia), Donald Goldberg (USA), Steven Hamburg (USA), Richard Houghton (USA), Paul Jarvis (UK), Timo Karjalainen (Finland), Haroon Kheshgi (USA), Thelma Krug (Brazil), Werner Kurz (Canada), Daniel Lashof (USA), Bo Lim (UNDP), Willy Makundi (Tanzania), Martin Manning (New Zealand), Gregg Marland(USA), Omar Masera (Mexico), Daniel Murdiyarso (Indonesia), Brian Murray (USA), Reidar Persson (Indonesia), Neil Sampson (USA), Jayant Sathaye (USA), Robert Scholes (South Africa), Bernhard Schlamadinger (Austria), Wim Sombroek (The Netherlands), Stephen Prisley (USA), John Stone (Canada), Raman Sukumar (India), and Riccardo Valentini (Italy) 


\section{Introduction}

1. Under Article 3.1 of the Kyoto Protocol, the Annex I Parties have agreed to limit and reduce their emissions of greenhouse gases between 2008 and 2012.

2. The Kyoto Protocol makes provision for Annex I Parties to take into account afforestation, reforestation, and deforestation (ARD) and other agreed land use, land-use change, and forestry (LULUCF) activities in meeting their commitments under Article 3.

3. To implement the Kyoto Protocol, issues related to LULUCF will have to be considered. Relevant issues may include for example:

- Definitions, including land-use change, forests, forestry activities, including afforestation, reforestation, and deforestation, carbon stocks, human-induced, and direct human-induced;

- Methodological issues, such as:

$>$ Rules for accounting for carbon stock changes and for emissions and removals of greenhouse gases from LULUCF activities, including:

- Which carbon pools to include;

- How to implement "since 1990," "direct human-induced," and "human-induced";

- How to address the risks and effects of events such as fires, pest outbreaks, and extreme meteorological events; baselines; permanence; interannual and decadal climate variability; and leakage;

- Accuracy, precision, and uncertainties in tracking carbon stocks and greenhouse gases;

$>$ Approaches, such as geo-referencing and statistical sampling, associated with identifying lands with activities defined under Article 3.3, accepted under Article 3.4, or associated with project-based activities under the Kyoto Protocol, and measuring and estimating changes in carbon stocks and greenhouse gases;

$>$ Verification procedures;

- Determination of how and which additional activities pursuant to Article 3.4 are included;

- How to link the first and subsequent commitment periods;

- Determination of how and which project-based activities are included;

- What improvements, if any, are needed to the Revised 1996 IPCC Guidelines for National Greenhouse Gas Inventories and the Good Practice Guidance and Uncertainty Management in National Greenhouse Gas Inventories;

- What are the implications of and what, if any, national and/or international sustainable development criteria could be associated with Articles 3.3 and 3.4 and project-based activities.
4. Therefore, to assist the Parties to the Protocol, this Summary for Policymakers (SPM) provides relevant scientific and technical information in three parts:

- Part I describes how the global carbon cycle operates and provides a context for the sections on ARD and additional human-induced activities;

- Part II addresses important issues regarding definitions and accounting rules. It identifies a range of options and discusses implications and interrelationships among options;

- Part III provides information that governments might find useful in considering these issues:

$>$ An assessment of the usefulness of models and of the usefulness and costs of ground-based and remotely-sensed measurements and of monitoring techniques for assessing changes in carbon stocks;

$>$ The near-term (first commitment period) potential for carbon stock changes/accounting of activities in Annex I countries and globally;

$>$ Issues of special significance to project-based activities;

$>$ An evaluation of the applicability of the Revised 1996 IPCC Guidelines for National Greenhouse Gas Inventories for national and project-level accounting in light of the Kyoto Protocol;

$>$ Implications of Articles 3.3 and 3.4 and project activities on sustainable development (i.e., socioeconomic and environmental considerations).

\section{Part I}

\section{Global Carbon Cycle Overview}

5. The dynamics of terrestrial ecosystems depend on interactions between a number of biogeochemical cycles, particularly the carbon cycle, nutrient cycles, and the hydrological cycle, all of which may be modified by human actions. Terrestrial ecological systems, in which carbon is retained in live biomass, decomposing organic matter, and soil, play an important role in the global carbon cycle. Carbon is exchanged naturally between these systems and the atmosphere through photosynthesis, respiration, decomposition, and combustion. Human activities change carbon stocks in these pools and exchanges between them and the atmosphere through land use, land-use change, and forestry, among other activities. Substantial amounts of carbon have been released from forest clearing at high and middle latitudes over the last several centuries, and in the tropics during the latter part of the 20th century. [1.1.1.2] ${ }^{1}$

6. There is carbon uptake into both vegetation and soils in terrestrial ecosystems. Current carbon stocks are much larger

1. Numbers in brackets at the end of this and subsequent paragraphs indicate relevant sections of the Special Report containing details. 
Table 1: Global carbon stocks in vegetation and soil carbon pools down to a depth of $1 \mathrm{~m}$.

\begin{tabular}{|c|c|c|c|c|}
\hline \multirow[b]{2}{*}{ Biome } & \multirow{2}{*}{$\begin{array}{c}\text { Area } \\
\left(\mathbf{1 0}^{9} \text { ha }\right)\end{array}$} & \multicolumn{3}{|c|}{ Global Carbon Stocks (Gt C) } \\
\hline & & Vegetation & Soil & Total \\
\hline Tropical forests & 1.76 & 212 & 216 & 428 \\
\hline Temperate forests & 1.04 & 59 & 100 & 159 \\
\hline Boreal forests & 1.37 & 88 & 471 & 559 \\
\hline Tropical savannas & 2.25 & 66 & 264 & 330 \\
\hline Tundra & 0.95 & 6 & 121 & 127 \\
\hline Wetlands & 0.35 & 15 & 225 & 240 \\
\hline Croplands & 1.60 & 3 & 128 & 131 \\
\hline Total & 15.12 & 466 & 2011 & 2477 \\
\hline
\end{tabular}

in soils than in vegetation, particularly in non-forested ecosystems in middle and high latitudes (see Table 1). [1.3.1]

7. From 1850 to 1998 , approximately $270(+30) \mathrm{Gt} \mathrm{C}$ has been emitted as carbon dioxide $\left(\mathrm{CO}_{2}\right)$ into the atmosphere from fossil fuel burning and cement production. About 136 (+55) $\mathrm{Gt} \mathrm{C}$ has been emitted as a result of land-use change, predominantly from forest ecosystems. This has led to an increase in the atmospheric content of carbon dioxide of 176 (+ 10) Gt C. Atmospheric concentrations increased from about 285 to 366 ppm (i.e., by $\sim 28 \%$ ), and about $43 \%$ of the total emissions over this time have been retained in the atmosphere. The remainder, about $230(+60) \mathrm{Gt} \mathrm{C}$, is estimated to have been taken up in approximately equal amounts in the oceans and the terrestrial ecosystems. Thus, on balance, the terrestrial ecosystems appear to have been a comparatively small net source of carbon dioxide during this period. [1.2.1]

8. The average annual global carbon budgets for 1980-1989 and 1989-1998 are shown in Table 2. This table shows that the rates and trends of carbon uptake in terrestrial ecosystems are quite uncertain. However, during these two decades, terrestrial ecosystems may have served as a small net sink for carbon dioxide. This terrestrial sink seems to have occurred in spite of net emissions into the atmosphere from land-use change, primarily in the tropics, having been $1.7 \pm$ $0.8 \mathrm{Gt} \mathrm{C} \mathrm{yr}^{-1}$ and $1.6 \pm 0.8 \mathrm{Gt} \mathrm{C} \mathrm{yr}^{-1}$ during these two decades, respectively. The net terrestrial carbon uptake, that approximately balances the emissions from land-use change in the tropics, results from land-use practices and natural regrowth in middle and high latitudes, the indirect effects of human activities (e.g., atmospheric $\mathrm{CO}_{2}$ fertilization and nutrient deposition), and changing climate (both natural and anthropogenic). It is presently not possible to determine the relative importance of these different processes, which also vary from region to region. [1.2.1 and Figure 1-1]
9. Ecosystem models indicate that the additional terrestrial uptake of atmospheric carbon dioxide arising from the indirect effects of human activities (e.g., $\mathrm{CO}_{2}$ fertilization and nutrient deposition) on a global scale is likely to be maintained for a number of decades in forest ecosystems, but may gradually diminish and forest ecosystems could even become a source. One reason for this is that the capacity of ecosystems for additional carbon uptake may be limited by nutrients and other biophysical factors. A second reason is that the rate of photosynthesis in some types of plants may no longer increase as carbon dioxide concentration continues to rise, whereas heterotrophic respiration is expected to rise with increasing temperatures. A third reason is that ecosystem degradation may result from climate change. These conclusions consider the effect of future $\mathrm{CO}_{2}$ and climate change on the present sink only and do not take into account future deforestation or actions to enhance the terrestrial sinks for which no comparable analyses have been made. Because of current uncertainties in our understanding with respect to acclimation of the physiological processes and climatic constraints and feedbacks amongst the processes, projections beyond a few decades are highly uncertain. [1.3.3]

10. Newly planted or regenerating forests, in the absence of major disturbances, will continue to uptake carbon for 20 to 50 years or more after establishment, depending on species and site conditions, though quantitative projections beyond a few decades are uncertain. [1.3.2.2]

11. Emissions of methane $\left(\mathrm{CH}_{4}\right)$ and nitrous oxide $\left(\mathrm{N}_{2} \mathrm{O}\right)$ are influenced by land use, land-use change, and forestry activities (e.g., restoration of wetlands, biomass burning, and fertilization of forests). Hence, to assess the greenhouse gas implications of LULUCF activities, changes in $\mathrm{CH}_{4}$ and $\mathrm{N}_{2} \mathrm{O}$ emissions and removals - the magnitude of which is highly uncertain — would have to be considered explicitly. There are currently no reliable global estimates of these emissions and removals for LULUCF activities. [1.2.2, 1.2.3, 3.3.2] 
Table 2: Average annual budget of CO for 1980 to 1989 and for 1989 to 1998, expressed in Gt C yr-1 (error limits correspond to an estimated $90 \%$ confidence interval).

\begin{tabular}{|c|c|c|}
\hline & 1980 to 1989 & 1989 to 1998 \\
\hline Emissions from fossil fuel combustion and cement production & $5.5 \pm 0.5$ & $6.3 \pm 0.6^{\mathrm{a}}$ \\
\hline 2) Storage in the atmosphere & $3.3 \pm 0.2$ & $3.3 \pm 0.2$ \\
\hline 3) Ocean uptake & $2.0 \pm 0.8$ & $2.3 \pm 0.8$ \\
\hline 4) Net terrestrial uptake $=(1)-[(2)+(3)]$ & $0.2 \pm 1.0$ & $0.7 \pm 1.0$ \\
\hline 5) Emissions from land-use change & $1.7 \pm 0.8$ & $1.6 \pm 0.8^{b}$ \\
\hline 6) Residual terrestrial uptake $=(4)+(5)$ & $1.9 \pm 1.3$ & $2.3 \pm 1.3$ \\
\hline $\begin{array}{l}\text { a Note that there is a one-year overlap (1989) between the two decadal time periods. } \\
\text { b This number is the average annual emissions for } 1989-1995 \text {, for which data are available. }\end{array}$ & & \\
\hline
\end{tabular}

\section{Part II}

\section{Issues Associated with Definitions}

12. For purposes of this Special Report, in a given land area and time period, a full carbon accounting system would consist of a complete accounting for changes in carbon stocks across all carbon pools. Applying full carbon accounting to all land in each country would, in principle, yield the net carbon exchange between terrestrial ecosystems and the atmosphere. However, the Kyoto Protocol specifies, among other things, that attention focus onto those land areas subject to “direct human-induced" activities since 1990 (Article 3.3) or human-induced activities (Article 3.4). [2.3.2.5]

\subsection{Forests, Afforestation, Reforestation, and Deforestation}

13. There are many possible definitions of a "forest" and approaches to the meaning of the terms "afforestation," "reforestation," and "deforestation" (ARD). The choice of definitions will determine how much and which land in Annex I countries are included under the provisions of Article 3.3, lands associated with activities included under Article 3.3 (hereafter "lands under Article 3.3"). The amount of land included will have implications for the changes in carbon stocks accounted for under Article 3.3. [2.2.2, 2.2.3, $3.2,3.5 .2,3.5 .3]$

14. Seven definitional scenarios were developed that combine definitions of forest and ARD and reflect a range of approaches that can be taken. The scenarios are not intended to be exhaustive. They can be split into two representative groups, which are discussed in the SPM: (1) scenarios in which only a forest/non-forest conversion (i.e., a land-use change triggers accounting under Article 3.3) (e.g., IPCC Definitional Scenario), and (2) scenarios in which landcover change or activities trigger accounting under Article 3.3 (e.g., FAO Definitional Scenario). [2.2.2, 2.2.3, 3.2, 3.5.2, 3.5.3, Table 3-4]
15. Countries have defined forests and other wooded lands, for a number of national and international purposes, in terms of (i) legal, administrative, or cultural requirements; (ii) land use; (iii) canopy cover; or (iv) carbon density (essentially biomass density). Such definitions were not designed with the Kyoto Protocol in mind and, thus, they may not necessarily suffice for the particular needs of Articles 3.3 and 3.4. $[2.2 .2,3.2]$

16. Forest definitions based on legal, administrative, or cultural considerations have limitations for carbon accounting as they may bear little relationship to the amount of carbon at a site. [2.2.2, 3.2]

17. Most definitions of forest are based in part on a single threshold of minimum canopy cover. However, such definitions may allow changes in carbon stocks to remain unaccounted under Article 3.3. For example, if a high threshold for canopy cover (e.g., 70\% canopy cover) is used in the definition of a forest, then many areas of sparse forest and woodland could be cleared or could increase in cover without the losses or gains in carbon being counted under Article 3.3. If a low threshold is set (e.g., $10 \%$ canopy cover), then dense forest could be heavily degraded and significant amounts of carbon released, without the actions being designated as deforestation. Similarly, a forest, for example with $15 \%$ canopy cover, could be considerably enhanced without the actions qualifying as reforestation or afforestation under Article 3.3. Approaches to address partly these problems may include, inter alia, using national, regional, or biome-specific thresholds (e.g., a low canopy cover for savannas and a high canopy cover for moist forests). [2.2.2, 3.2, 3.3.2]

18. Definitions of forests based on carbon-density thresholds have similar issues with respect to thresholds as canopy cover-based definitions. [2.2.2]

19. There are a number of approaches to definitions of afforestation, reforestation, and deforestation. One approach involves 
the concept of land-use change. Deforestation can be defined as the conversion of forest land to non-forest land. Reforestation and afforestation can be defined as the conversion of non-forested lands to forests with the only difference being the length of time during which the land was without forest. [2.2.3, 3.2]

20. An alternative definition of deforestation might be based on a decrease in the canopy cover or carbon density by a given amount or crossing one of a sequence of thresholds. Similarly, afforestation and reforestation could be defined in terms of an increase in canopy cover or carbon density. None of these definitions involves the concept of a land-use change. [2.2.2, 3.2]

21. Definitions of a forest based strictly on actual canopy cover without consideration of potential canopy cover could lead to harvesting and shifting agriculture being referred to as deforestation and to regeneration being referred to as reforestation, thus creating additional areas of lands under Article 3.3. If the definition of a forest was based on the potential canopy cover at maturity under planned land-use practices, harvesting/regeneration activities may not fall under Article 3.3. $[2.2 .2,2.2 .3,3.2]$

22. Some commonly used definitions of reforestation include the activity of regenerating trees immediately after disturbance or harvesting where no land-use change occurs. If, for example, the definition of deforestation or the accounting system do not include disturbance and harvesting, then emissions from a harvested stand will not be accounted for. In this particular example, uptake due to regeneration would be accounted for, resulting in potentially significant credits for which a corresponding net removal of carbon from the atmosphere would not occur. This issue could be considered when developing the accounting system. [2.2.3.2]

23. There are several consequences of using definitions that lead to the creation of lands under Article 3.3 by the harvestregeneration cycle (i.e., where harvesting is included in the definition of deforestation, or regeneration is included in the definition of reforestation). For example, a forest estate managed on a sustainable-yield basis where an area of forest is cut in a regular cycle (e.g., 1/50th of the forest is harvested and regenerated each year on a 50-year rotation cycle) may be in approximate carbon balance. However, in this case, only those stands harvested or regenerated since 1990 would be considered lands under Article 3.3. The regrowth (carbon sink) on these lands will be less than the carbon emissions due to harvesting until all stands of the estate are lands under Article 3.3. Different definitional and accounting approaches would have different accounting consequences. For example:

- If emissions from harvesting during a commitment period are counted (land-based approach I; see Table 3), then during the first and subsequent commitment periods a net debit could arise from a managed forest estate that is approximately in carbon balance;
- If emissions from harvesting during a commitment period prior to regeneration are not counted (landbased approach II; see Table 3), then during the first and subsequent commitment periods a net credit would generally arise from a managed forest estate that is approximately in carbon balance. This may be offset to some extent by delayed emissions from soils and harvest residues;

- If emissions from harvesting during a commitment period are not counted (activity-based approach; see Table 3), then during the first and subsequent commitment periods a net credit would arise from regeneration in a managed forest estate that is approximately in carbon balance. It would be practically very difficult to separate changes in soil carbon pools associated with harvesting and regeneration activities.

In each of these approaches the accounted stock changes would generally be different from the actual net exchange of carbon between this example forest estate and the atmosphere during a commitment period. [3.2, 3.5.2]

24. Afforestation is usually defined as the establishment of forest on land that has been without forest for a period of time (e.g., 20-50 years or more) and was previously under a different land use. The precise period that distinguishes afforested from reforested land is not important in accounting for lands covered under Article 3.3 provided afforestation and reforestation are treated identically under the Protocol, as they are in the Revised 1996 IPCC Guidelines for National Greenhouse Gas Inventories. ${ }^{2}$ [2.2.3, 3.3.2]

25. Article 3.3 encompasses ARD activities that have occurred since 1990 but recognizes only verifiable carbon stock changes in each commitment period. This has several implications. For example:

- For lands deforested between 1990 and the beginning of the first commitment period only a fraction of carbon stock changes (such as those from delayed carbon emissions from soil and wood products if they are accounted) will occur during the commitment period and would be debited under Article 3.3. If these

2. The Glossary of the Revised 1996 IPCC Guidelines describes afforestation as "Planting of new forests on lands which, historically, have not contained forests. These newly created forests are included in the category Changes in Forest and Other Woody Biomass Stocks in the Land Use Change and Forestry module of the emissions inventory calculations" and reforestation as "Planting of forests on lands which have, historically, previously contained forests but which have been converted to some other use. Replanted forests are included in the category Changes in Forest and Other Woody Biomass Stocks in the Land Use Change and Forestry module of the emissions inventory calculations." Deforestation does not appear in the Glossary of the Revised 1996 IPCC Guidelines. The Revised 1996 IPCC Guidelines state, referring to land-use change, that "Conversion of forests is also referred to as 'deforestation' and it is frequently accompanied by burning." The Revised 1996 IPCC Guidelines were developed before the Kyoto Protocol was adopted and therefore provisions may not be sufficient to meet the needs of the Kyoto Protocol. 


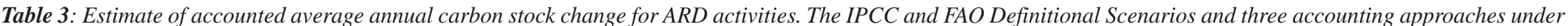

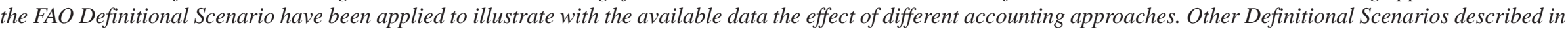

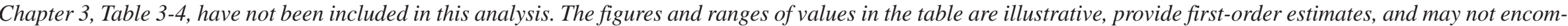
pass the full range of uncertainties. Negative numbers indicate carbon emissions and positive numbers carbon removals. For details, see Table 3-17 in Chapter 3.

\begin{tabular}{|c|c|c|c|c|c|c|c|c|}
\hline Region & Activity & $\begin{array}{c}\text { AR Average } \\
\text { Rate of Uptake } \\
(\text { t C ha-1 yr-1); } \\
\text { D Average Stock } \\
\quad(\mathrm{t} \mathrm{C} \mathrm{ha-1)}\end{array}$ & \multicolumn{2}{|c|}{\begin{tabular}{cc}
\multicolumn{1}{c}{ Area Change } & Mha $\mathbf{y r}^{-1}$ ) \\
& $\begin{array}{c}\text { Conversion } \\
\text { between }\end{array}$ \\
Post-Harvest & Non-Forest \\
Regeneration & and Forest
\end{tabular}} & \multicolumn{4}{|c|}{$\begin{array}{l}\text { Estimated Range of Accounted Average Annual Stock } \\
\left.\text { Change 2008-2012 (Mt C } \mathbf{y r}^{-\mathbf{1}}\right) \\
\text { Includes carbon in aboveground and below-ground biomass, } \\
\text { excludes carbon in soils and in dead organic matter }\end{array}$} \\
\hline $\begin{array}{l}\text { Boreal Region } \\
\text { Total (=Annex I) }\end{array}$ & $\begin{array}{l}\text { AR } \\
\text { D } \\
\text { Total ARD }\end{array}$ & $\begin{array}{l}0.4 \text { to } 1.2 \\
35\end{array}$ & 3.1 & $\begin{array}{l}0.1 \\
0.5\end{array}$ & $\begin{array}{l}-209 \text { to }-162 \\
-18 \\
-227 \text { to }-180\end{array}$ & $\begin{array}{l}-56 \text { to }-8 \\
-18 \\
-74 \text { to }-26\end{array}$ & $\begin{array}{l}5 \text { to } 48 \\
\quad-18 \\
-13 \text { to } 30\end{array}$ & $\begin{array}{l}0 \text { to } 2 \\
-18 \\
-18 \text { to }-16\end{array}$ \\
\hline $\begin{array}{l}\text { Temperate Region } \\
\text { Annex I }\end{array}$ & $\begin{array}{l}\text { AR } \\
\text { D } \\
\text { Total ARD }\end{array}$ & $\begin{array}{l}1.5 \text { to } 4.5 \\
60\end{array}$ & 5.4 & $\begin{array}{l}0.5 \\
1.2\end{array}$ & $\begin{array}{l}-550 \text { to }-81 \\
-72 \\
-622 \text { to }-153\end{array}$ & $\begin{array}{l}-134 \text { to } 303 \\
-72 \\
-206 \text { to } 231\end{array}$ & $\begin{array}{l}81 \text { to } 519 \\
-72 \\
9 \text { to } 447\end{array}$ & $\begin{array}{c}7 \text { to } 44 \\
-72 \\
-65 \text { to }-28\end{array}$ \\
\hline Annex I Total & $\begin{array}{c}\text { AR } \\
\text { D } \\
\text { Total ARD }\end{array}$ & & 8.5 & $\begin{array}{l}0.6 \\
1.7\end{array}$ & $\begin{array}{c}-759 \text { to }-243 \\
-90 \\
-849 \text { to }-333\end{array}$ & $\begin{array}{c}-190 \text { to } 295 \\
-90 \\
-280 \text { to } 205\end{array}$ & $\begin{array}{l}87 \text { to } 573 \\
-90 \\
-3 \text { to } 483\end{array}$ & $\begin{array}{c}7 \text { to } 46 \\
-90 \\
-83 \text { to }-44\end{array}$ \\
\hline $\begin{array}{l}\text { Temperate Region } \\
\text { Total }\end{array}$ & $\begin{array}{c}\text { AR } \\
\text { D } \\
\text { Total ARD }\end{array}$ & $\begin{array}{l}1.5 \text { to } 4.5 \\
60\end{array}$ & $\mathrm{n} / \mathrm{a}$ & $\begin{array}{l}1.9 \\
2.1\end{array}$ & $\begin{array}{c}\mathrm{n} / \mathrm{a} \\
-126 \\
\mathrm{n} / \mathrm{a}\end{array}$ & $\begin{array}{c}\mathrm{n} / \mathrm{a} \\
-126 \\
\mathrm{n} / \mathrm{a}\end{array}$ & $\begin{array}{c}\mathrm{n} / \mathrm{a} \\
-126 \\
\mathrm{n} / \mathrm{a}\end{array}$ & $\begin{array}{l}27 \text { to } 167 \\
-126 \\
-99 \text { to } 41\end{array}$ \\
\hline $\begin{array}{l}\text { Tropical Region } \\
\text { Total }\end{array}$ & $\begin{array}{c}\text { AR } \\
\text { D } \\
\text { Total ARD }\end{array}$ & $\begin{array}{c}4 \text { to } 8 \\
120\end{array}$ & $\mathrm{n} / \mathrm{a}$ & $\begin{array}{c}2.6 \\
13.7\end{array}$ & $\begin{array}{c}\mathrm{n} / \mathrm{a} \\
-1644 \\
\mathrm{n} / \mathrm{a}\end{array}$ & $\begin{array}{c}\mathrm{n} / \mathrm{a} \\
-1644 \\
\mathrm{n} / \mathrm{a}\end{array}$ & $\begin{array}{c}\mathrm{n} / \mathrm{a} \\
-1644 \\
\mathrm{n} / \mathrm{a}\end{array}$ & $\begin{array}{c}170 \text { to } 415 \\
-1644 \\
-1474 \text { to }-1229\end{array}$ \\
\hline $\begin{array}{l}\text { Global Total } \\
\text { (summing regional } \\
\text { totals) }\end{array}$ & $\begin{array}{c}\text { AR } \\
\text { D } \\
\text { Total ARD }\end{array}$ & & $\mathrm{n} / \mathrm{a}$ & $\begin{array}{l}4.6 \\
16.3\end{array}$ & $\begin{array}{c}\mathrm{n} / \mathrm{a} \\
-1788 \\
\mathrm{n} / \mathrm{a}\end{array}$ & $\begin{array}{c}\mathrm{n} / \mathrm{a} \\
-788 \\
\mathrm{n} / \mathrm{a}\end{array}$ & $\begin{array}{c}\mathrm{n} / \mathrm{a} \\
-1788 \\
\mathrm{n} / \mathrm{a}\end{array}$ & $\begin{array}{c}197 \text { to } 584 \\
-1788 \\
-1591 \text { to }-1204\end{array}$ \\
\hline
\end{tabular}

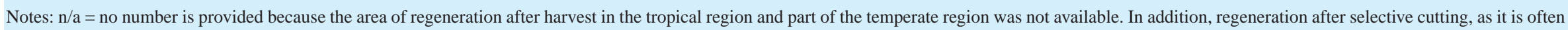

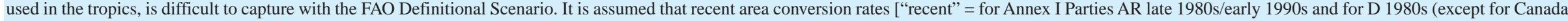

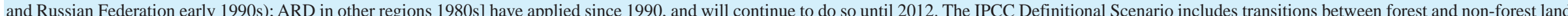

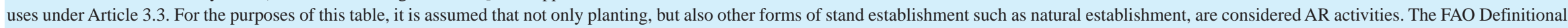

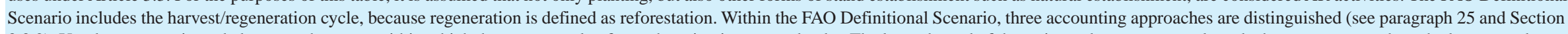

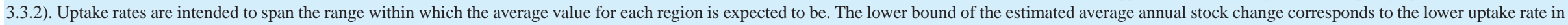

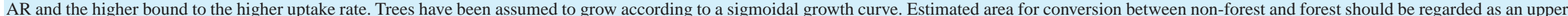

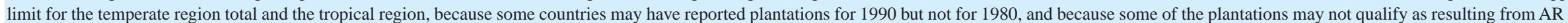
activities under the IPCC Definitional Scenario. Also, for tropical countries, the deforestation estimates are very uncertain and could be in error by as much as $\pm 50 \%$. 
lands are subsequently reforested then there may be an increase in carbon stocks during the commitment period and a credit under Article 3.3. This would mean that the credit received would not match the actual carbon stock changes or the net exchanges of carbon with the atmosphere since 1990;

- Another accounting issue could arise when land is reforested or afforested between 1990 and 2008 but stocks are reduced either by harvesting or natural disturbance during a commitment period. Even though the forest area and possibly carbon stocks may have increased since 1990, a debit could be recorded in a commitment period. This creates the possibility of a negative incentive for establishing forests well in advance of the first commitment period, because any stock increase prior to 2008 would not be credited but the later loss of this stock would be debited.

Such outcomes could possibly be addressed through different combinations of definitional and accounting approaches. [3.3.2]

26. There are definitional and carbon accounting issues concerning drawing a clear boundary between natural phenomena and human-induced activities, when, for example, significant forest losses occur as a result of fires or disturbances such as pest outbreaks. In cases involving lands under Article 3.3 or 3.4 where fires or pest outbreaks occur in a forest, a question is whether accounting should, inter alia: (i) count neither the loss nor subsequent uptake of carbon (which reflects the actual net change in carbon stocks on those lands and exchange of carbon with the atmosphere in the long term, but creates problems in continuing to account for the area burnt/defoliated as lands under Article 3.3 or 3.4); (ii) count both the loss and subsequent uptake of carbon (which reflects the actual net change in carbon stocks on those lands and exchange of carbon with the atmosphere, but creates an initial carbon debit for the Party concerned); (iii) count only the loss of carbon (which would overestimate the actual losses of carbon stocks, not represent the exchanges of carbon with the atmosphere, and create future accounting problems); or (iv) count only the subsequent uptake (which would fail to reflect the actual changes in carbon stock and would not represent the exchanges of carbon with the atmosphere, and would provide carbon credits for the Party concerned). [2.2.3.3]

27. In cases involving lands that do not fall under Articles 3.3 or 3.4 , where fires or pest outbreaks trigger land-use change, the consequences are similar to deforestation. If similar vegetation cover is allowed to regenerate, such disturbances may not lead to a long-term change in carbon stocks. [2.4.4, 2.2.3, 2.3.3]

\subsection{Additional Activities ${ }^{3}$}

28. When the inclusion of additional activities under Article 3.4 is considered, it is possible to interpret "activity" broadly (e.g., cropland management) or narrowly (e.g., change in tillage method, fertilization, or cover crops). Under either interpretation, it is, in principle, possible to choose either a land-based or an activity-based method of carbon accounting or a combination of both (see Section 4). These combined choices will affect the accuracy, feasibility, cost, transparency, and verifiability of monitoring and reporting of emissions and removals, including non- $\mathrm{CO}_{2}$ greenhouse gases, and attributing them to specific activities. [2.3.2.2, 4.3.1, 4.3.2]

29. The term "broad activity" means an activity definition that is land- or area-based, where the net effect of all practices applied within the same area are included. A broad activity definition is likely to require land-based accounting (see paragraph 34). This definitional approach would capture the net emission or removal effects of practices that deplete carbon stocks as well as those that increase removals by sinks. Broad activity definitions, particularly in cases where land-use change is involved, may make it difficult to separate human-induced changes from naturally-induced changes. $[2.3 .2,4.3 .2]$

30. The narrow definition of "activity" is based on individual practices, such as reduced tillage or irrigation water management. The narrow definition may lend itself to activitybased accounting, but land-based accounting is also possible. Under activity-based accounting, discrete definitions and associated rates of emissions or removals are needed for each individual practice. Narrow definitions raise the potential for multiple activities to occur on a single land area, raising accounting issues (see paragraph 33). Narrow activity definitions may facilitate the separation of human-induced changes from natural influences (see paragraph 45). [4.2.1, 4.3.2, 4.3.4]

\section{Carbon Accounting}

31. A well-designed carbon accounting system would provide transparent, consistent, comparable, complete, accurate, verifiable, and efficient recording and reporting of changes in carbon stocks and/or changes in greenhouse gas emissions by sources and removals by sinks from applicable land use, land-use change, and forestry activities and projects under relevant Articles of the Kyoto Protocol. Such data would be needed to assess compliance with the commitments under the Kyoto Protocol. Two possible accounting approaches towards meeting these requirements are outlined below, of which either one - or combination of the two - could be adopted (see Figure 1). [2.3.1]

32. A "land-based" approach to accounting would take as its starting point the change in carbon stock in applicable carbon pools on lands containing activities included under

3. The technical issues addressed in paragraph 26 also apply to additional activities adopted under Article 3.4, but are not repeated here for conciseness. 
Land-Based Accounting

Activity-Based Accounting

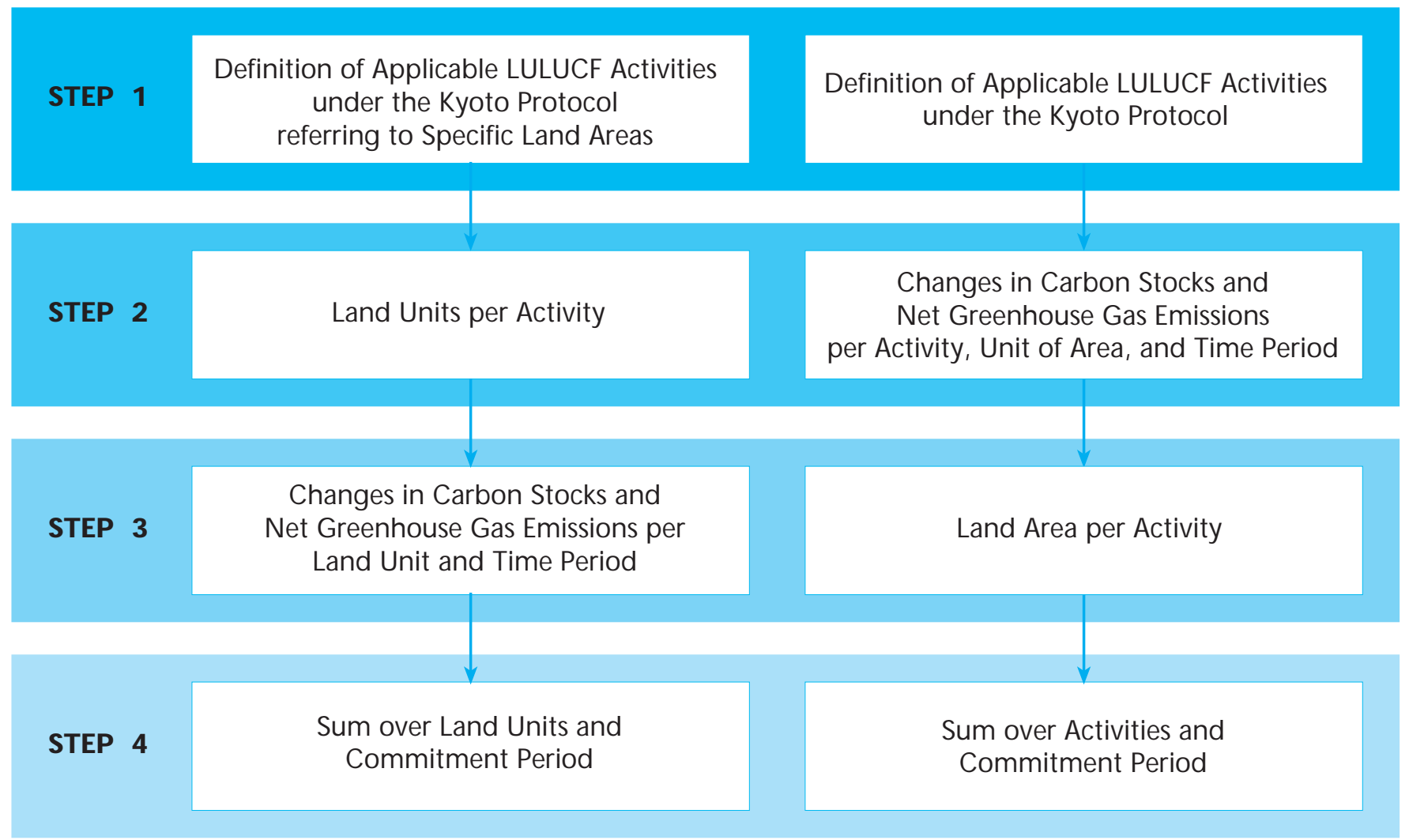

Figure 1: Accounting approaches.

Article 3.3 or accepted under Article 3.4. This involves first defining the applicable activities, and in the next step identifying the land units on which these activities occur. Next, the change in carbon stocks on these land units during the relevant period is determined. In the land-based approach, it could be difficult to factor out the impact on stocks of indirect effects (see paragraph 44). Non- $\mathrm{CO}_{2}$ greenhouse gas emission estimates would also need to be accounted for. Modifications could be made regarding, for example, baselines, leakage, timing issues, permanence, and uncertainties. Aggregate accounted $\mathrm{CO}_{2}$ emissions and removals are the sum of carbon stock changes (net of any modifications) over all applicable land units over the specified time period. $[2.3 .2,3.3 .2]$

33. An "activity-based" approach to accounting would start with the carbon stock change in applicable carbon pools and/or emissions/removal of greenhouse gases attributable to designated LULUCF activities. After defining the applicable activities, each applicable activity's impact on carbon stocks is determined per unit area and time unit. This impact is multiplied by the area on which each activity occurs and by the years it is applied or the years of the commitment period. Modifications could be made regarding, for example, baselines, leakage, timing issues, permanence, and uncertainties. Aggregate accounted emissions and removals are calculated by summing across applicable activities. Potentially a given area of land could be counted more than once if it is subject to multiple activities. If the effects of activities are not additive, this would result in inaccurate accounting. In this case, the carbon stock would be especially difficult to verify. Alternatively, the Parties could decide that each land unit could contain no more than a single activity. In this case, the combined impact of multiple practices applied in the same area would be considered a single activity. [2.3.2, 3.3.2, 4.3.3]

34. The land-based approach to accounting could start either with the start of the activity or run for the entire commitment period, while the activity-based approach would start when the activity starts or at the beginning of the commitment period, whichever is later. Either accounting approach could end according to decisions that the Parties might adopt. In the activity-based approach, stock changes prior to the start of the activity would not be accounted, even if they occur in a commitment period. [2.3.2]

35. Some activities must be persistently maintained to retain the stored carbon stocks, and this may influence the accounting methods required. Conservation tillage, for example, may increase carbon stocks on cropland if carried on continuously, but where it is practiced for a time, then interrupted by a year of intensive tillage brought on by, for example, a weather situation or crop change, much of the previous multi-year gain in soil carbon can be lost. Land-based estimates of the cropland estate should reflect the net effect of 
those gains and losses over the full area during the accounting period and give verifiable results, provided statistically representative sampling procedures are in place. If activitybased accounting occurs without sampling, it may report results inconsistent with actual stock changes during the accounting period. [2.3.2]

36. For technical reasons, only emissions and removals of $\mathrm{CO}_{2}$ can be determined directly as changes in carbon stocks. Methane emissions and removals cannot in practice be directly measured as carbon stock changes, although $\mathrm{CH}_{4}$ and $\mathrm{N} 2 \mathrm{O}$ can be determined by other means. Methane and nitrous oxide emissions from many land-use activities are included in Annex A of the Kyoto Protocol (e.g., rice cultivation, enteric fermentation, and agricultural soils) and in the Revised 1996 IPCC Reporting Guidelines for National Greenhouse Gas Inventories, and therefore they will be captured in national inventories. This is not the case, however, for emissions of these gases related to forestry activities and projects, which are not included in Annex A, although some of these forestry activities are discussed in the 1996 Revised IPCC Guidelines for National Greenhouse Gas Inventories. If the net emissions of $\mathrm{CH}_{4}$ and $\mathrm{N}_{2} \mathrm{O}$ are not considered, the full climate impact of forestry activities may not be reflected in the accounting system under the Kyoto Protocol. The treatment of $\mathrm{CH}_{4}$ and $\mathrm{N}_{2} \mathrm{O}$ emissions under Article 3.3 may deserve further consideration and clarification. For agreed activities, Article 3.4 leaves open how net greenhouse gas emissions will be accounted for in meeting the commitments under Article 3.1 of the Protocol. [2.3.2, 3.3.2]

37. Relevant carbon pools could include aboveground biomass, litter and woody debris, below-ground biomass, soil carbon, and harvested materials. The impact on these different carbon pools may vary significantly between activities and types of projects. While methods exist to measure all carbon pools, to date monitoring is not routinely performed on all pools and the costs vary significantly. A conservative approach that would allow for selective accounting of carbon pools to reduce monitoring costs could be to include all those pools anticipated to have reduced carbon stocks while omitting selected pools anticipated, with a sufficient level of certainty, to have unchanged or increased carbon stocks. Similar approaches could be used for fluxes of non- $\mathrm{CO}_{2}$ greenhouse gases. Under this approach, verifiability would mean that only increases in carbon stocks and removal by sinks that can be monitored and estimated could potentially be credited. [2.3.7, 3.3.2, 4.2.1]

38. Accounting for LULUCF activities under Articles 3.3 and 3.4 includes different types of uncertainties, including measurement uncertainty, uncertainty in identifying lands under Article 3.3 or 3.4, and uncertainty in defining and quantifying baselines, if any. This uncertainty can be accounted for in several ways. One approach is to extend the application of good practice guidance in the choice of methods and handling of uncertainty in estimates which has been developed by the IPCC for other inventory categories. Another approach could be to adjust estimated stock changes in a conservative way - understating increases and overstating decreases in stocks. The latter option could allow tradeoffs between monitoring costs and the potential to receive increased carbon credits or reduced debits, but would not be consistent with established principles for estimation of emissions and removals in greenhouse gas inventories. [2.3.7]

39. Changes in carbon stocks in wood products could potentially be accounted as part of the activity that is the source of the wood products or as an independent wood products management activity. If management of wood products is treated as an additional activity under Article 3.4, then it may be necessary to exclude wood products from accounting under other Article 3.3 or 3.4 activities to avoid double-counting. Once wood products are in trade, they would be difficult in most instances to trace. The current IPCC default approach assumes that the wood product pool remains constant over time, and therefore does not account for it. However, if this pool is changing significantly over time, a potentially important pool may not be accounted for. [2.4.2, 3.3.2, 4.5.6, 6.3.3]

40. Enhancement of carbon stocks resulting from land use, land-use change, and forestry activities is potentially reversible through human activities, disturbances, or environmental change, including climate change. This potential reversibility is a characteristic feature of LULUCF activities in contrast to activities in other sectors. This potential reversibility and nonpermanence of stocks may require attention with respect to accounting, for example, by ensuring that any credit for enhanced carbon stocks is balanced by accounting for any subsequent reductions in those carbon stocks, regardless of the cause. [2.3.6, 3.3.2]

41. Contiguous commitment periods under the Kyoto Protocol would avoid incentives in subsequent periods to concentrate activities that reduce carbon stocks in time periods that were not covered. [2.3.2]

42. Policies by governments or other institutions (e.g., land tenure reform and tax incentives) may provide a framework and incentives for implementing LULUCF activities. Changes in markets may also affect the economic conditions for land use, land-use change, and forestry activities. The ability to measure the impact of these conditions and incentives will depend, in part, upon the carbon inventory and monitoring system in each country. However, it may be very difficult for countries to assess the relative impact of policies by governments or other institutions compared to other human and natural factors that drive changes in carbon stocks. [2.3.5, 5.2.2]

43. Natural variability, such as El Niño cycles, and the indirect effects of human activity, such as $\mathrm{CO}_{2}$ fertilization, nutrient deposition, and the effects of climate change, could significantly affect carbon stocks during a commitment period on lands under Article 3.3 or 3.4. The spatial distribution of 
the emissions and removals of greenhouse gases due to these factors is uncertain, as is the portion of them that may enter the accounting system. These emissions and removals could be potentially large compared to the commitments in the first commitment period. This could be a significant issue in the design of an accounting framework. [2.3.3]

44. The Kyoto Protocol specifies that accounting under Article 3.3 be restricted to "direct human-induced land-use change and forestry activities, limited to afforestation, reforestation, and deforestation" occurring since 1990. For activities that involve land-use changes (e.g., from grassland/ pasture to forest) it may be very difficult, if not impossible, to distinguish with present scientific tools that portion of the observed stock change that is directly human-induced from that portion that is caused by indirect and natural factors. $[2.3 .4,3.3 .2]$

45. For those activities where only narrowly defined management changes under Article 3.4 are involved (e.g., conservation tillage) and the land use remains the same, it may be feasible to factor out partially natural variability and indirect effects. One approach may be to subtract the stock changes on comparison plots where there have been no changes in management practice from changes measured on plots with modified management activities. In most cases, experimental manipulation or paired plots can be used for this purpose, but they are likely to be expensive to apply over large areas. Ecosystem models can also be used but need further improvement to decrease uncertainties. Verifiability could be assisted by the application of a combination of models and measurements. [2.3.4, 4.3.4]

46. Baselines could be used in some cases to distinguish between the effects of LULUCF activities and other factors, such as natural variability and the indirect effects of human activities, as well as to factor out the effects of business-as-usual and activities undertaken prior to 1990 on carbon stock accounts and net greenhouse gas emissions. If the concept of a baseline was to be applied in national accounting for activities under Article 3.4, there are many options, which include: (i) the stock/flux change that would have resulted from "business-as-usual" activities; (ii) the stock/flux change that would have resulted from the continuation of 1990 activity levels; (iii) the stock/flux change that would result in the absence of active management; (iv) performance benchmarks or standard management practice; and (v) the rate of change of stocks/fluxes in 1990. The first three of these baseline options may involve the use of a counterfactual scenario. One difficulty with the use of counterfactual baselines is verification. [2.3.4, 4.6, 4.6.3.3]

47. Accounting under the terms land-use change and forestry in Article 3.7 will determine which emissions and removals of carbon will enter the 1990 base year or period for some countries. If the land-use change activities giving rise to these emissions and removals are not included under
Article 3.3 or 3.4 during the commitment periods, then the inventories of countries subject to this clause in Article 3.7 would not be calculated on the same basis as their 1990 emissions base year or period. [3.3.2]

48. If different accounting rules are adopted for relevant Articles of the Kyoto Protocol, additional decision rules may be needed to determine which accounting rule applies to land that, over time, is subject to multiple types of activities. For example, one set of accounting rules could be given primacy in cases where more than one set could potentially apply and double-counting might result. [2.3.2, 3.3.2]

49. Leakage is changes in emissions and removals of greenhouse gases outside the accounting system that result from activities that cause changes within the boundary of the accounting system. There are four types of leakage: activity displacement, demand displacement, supply displacement, and investment crowding. If leakage occurs, then the accounting system will fail to give a complete assessment of the true aggregate changes induced by the activity. Although leakage is in many cases a negative effect, situations, such as the demonstration effect of new management approaches or technology adoption, may occur where the emissions reductions or removals of greenhouse gases extend beyond the accounting system boundaries (positive spillover effect). For some activities and project types, leakage may be addressed by increasing the spatial and temporal scale of the accounting system boundaries (i.e., by including areas where changes in removal and emissions of greenhouse gases may be induced). However, leakage may extend beyond any activity accounting boundaries (e.g., beyond national boundaries). Leakage is of particular concern in project-level accounting, but may also occur with activities under Articles 3.3 and 3.4. [2.3.5.2, 5.3.3]

\section{Part III}

\section{Methods for Measuring and Monitoring}

50. Lands under Articles 3.3 and 3.4 could be identified, monitored, and reported using geographical and statistical information. Changes in carbon stocks and net greenhouse gas emissions over time can be estimated using some combination of direct measurements, activity data, and models based on accepted principles of statistical analysis, forest inventory, remote-sensing techniques, flux measurements, soil sampling, and ecological surveys. These methods vary in accuracy, precision, verifiability, cost, and scale of application. The cost of measuring changes in carbon stocks and net greenhouse gas emissions for a given area increases as both desired precision and landscape heterogeneity increase. [2.4, 3.4]

51. The spatial resolution of monitoring has important implications for accuracy and costs. If a small minimum 
resolvable land area is used, the task and cost of monitoring can become very demanding. If the spatial resolution is set at a coarse scale, the data demands can be modest, but significant areas subject to an activity may be lost in the averaging process. For example, if forests and deforestation are defined in terms of canopy cover and canopy cover is assessed over land areas of 100 ha, then deforestation of smaller areas within a unit may not take the canopy cover of the unit below the forest definition threshold. Thus, changes in carbon stocks may not be accounted and, likewise, afforestation or reforestation of small areas may not be accounted. Hence, there are clear tradeoffs between an accurate and precise assessment of changes in carbon stocks and cost. However, an appropriate design should result in a statistically reliable estimate. [2.2.2]

52. The technical capacity required by Annex I Parties to measure, monitor, and verify carbon stock changes and net greenhouse gas emissions under the Kyoto Protocol will be significantly affected by decisions of the Parties regarding definitions of key terms related to land use, land-use change, and forestry activities. It will also depend on decisions on, inter alia, additional activities that may be included under Article 3.4, and whether additional activities are defined broadly or narrowly. Depending upon decisions that may be made, establishing a monitoring, reporting, and verification system under Articles 3.3 and 3.4 is likely to involve a significant effort by Annex I Parties, given the technology, data, and resources required, and the short time available. $[2.4 .1,3.4,4.3 .2,4.3 .5]$

53. Annex I Parties generally have the basic technical capacity (soil and forest inventories, land-use surveys, and information based on remote-sensing and other methods) to measure carbon stocks and net greenhouse gas emissions in terrestrial ecosystems. However, few, if any, countries perform all of these measurements routinely, particularly soil inventories. Some Annex I Parties may use existing capacity with minimal modification to implement the various Articles in the Kyoto Protocol; however, some other Annex I Parties may need to improve significantly their existing measurement systems in order to develop operational systems. Non-Annex I Parties may require technical, institutional, and financial assistance and capacity building for measuring, monitoring, and verifying carbon stock changes as well as for estimating net greenhouse gas emissions. [2.4.6, 3.4.3, 4.2]

54. Technical methods for measuring and estimating changes in forest carbon stocks in aboveground biomass over a five-year commitment period may be deemed to be sensitive enough to serve the requirements of the Protocol. Sensitive methods for estimating below-ground carbon stocks also exist. However, changes in soil carbon stocks are in some instances small and difficult to assess accurately over a five-year time period. This problem may be addressed by adopting appropriate sampling techniques supported by modeling that take into account spatial variability. Methods that further improve estimates of soil and vegetation carbon stock will depend on future research and model development and are likely to be highly transferable between Parties. [2.4.2, 2.4.3, 4.2.2, 5.4.1]

\section{Estimates of Average Annual Carbon Stock Changes/Accounted for ARD Activities and Some Additional Activities}

\subsection{Afforestation, Reforestation, and Deforestation}

55. Different definitions and accounting approaches under Article 3.3 of the Kyoto Protocol produce different estimates of changes in carbon stocks. There are seven Definitional Scenarios described in Chapter 3 of the underlying report. Table 3 illustrates, with data and methods available at the time of the Special Report, the estimated carbon stock changes accounted from ARD activities under the IPCC and FAO Definitional Scenarios, assuming recent area conversion rates remain constant and excluding carbon in soils and wood products. Three different carbon accounting approaches have been applied to the FAO Definitional Scenario to illustrate the effect of different accounting approaches. [3.5.3, 3.5.4, Table 3-4, Table 3-17]

56. The IPCC Definitional Scenario yields estimates of average annual accounted carbon stock changes from afforestation and reforestation in Annex I Parties from 2008 to 2012 of 7 to $46 \mathrm{Mt} \mathrm{C} \mathrm{yr}^{-1}$. This would be offset by annual changes in carbon stocks from deforestation of about $-90 \mathrm{MtC}^{-1}$, producing a net stock change of -83 to $-44 \mathrm{Mt} \mathrm{C} \mathrm{yrr}^{-1}$. If hypothetically, for example, afforestation and reforestation rates were to be increased in Annex I Parties by $20 \% 4$ for the years 2000 to 2012, estimated annual changes in carbon stocks would increase (from 7 to $46 \mathrm{Mt} \mathrm{Cyrr}^{-1}$ ) to 7 to $49 \mathrm{Mt}$ $\mathrm{C} \mathrm{yrr}^{-1}$. If hypothetically, for example, deforestation rates were to be decreased by $20 \%$, estimated annual losses of carbon stocks due to deforestation would reduce (from $-90 \mathrm{Mt}$

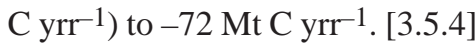

57. The three accounting approaches under the FAO Definitional Scenario yield different results. Estimated average annual carbon stock changes in Annex I Parties from afforestation

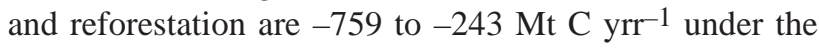
FAO land-based I approach; -190 to $295 \mathrm{Mt} \mathrm{C} \mathrm{yrr}^{-1}$ under the FAO land-based II approach; and 87 to $573 \mathrm{Mt} \mathrm{C} \mathrm{yr}^{-1}$ under the FAO activity-based approach. Estimated average annual carbon stock changes from deforestation are about $-90 \mathrm{Mt}$ $\mathrm{C} \mathrm{yrr}^{-1}$ in all three approaches, as in the IPCC Definitional Scenario. [3.5.4]

58. For comparison, the IPCC Definitional Scenario yields estimates of average annual accounted carbon stock changes from afforestation and reforestation globally from 2008 to 2012 of 197 to $584 \mathrm{Mt} \mathrm{C} \mathrm{yr}^{-1}$. This would be offset

4. The $20 \%$ is an arbitrary value chosen to show the sensitivity of the estimates to changes in practices. 
by annual changes in carbon stocks from deforestation of about $-1788 \mathrm{Mt} \mathrm{C} \mathrm{yrr}^{-1}$, producing a net stock change of

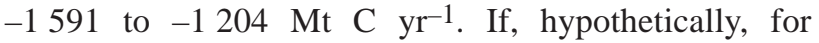
example, afforestation and reforestation rates were to be increased globally by $20 \%$ for the years 2000 to 2012, estimated annual changes in carbon stocks would increase (from 197 to $584 \mathrm{Mt} \mathrm{C} \mathrm{yr}^{-1}$ ) to 208 to $629 \mathrm{Mt} \mathrm{C} \mathrm{yr}^{-1}$. [3.5.4]

59. In the IPCC Definitional Scenario and FAO Definitional Scenario with land-based I accounting approach, the accounted carbon stock changes are broadly consistent with the 2008-2012 actual changes in carbon stocks from land under Article 3.3. The IPCC and FAO Definitional Scenarios bring different amounts of land under Article 3.3, hence the estimated carbon stock changes in Table 3 differ.

60. In the FAO Definitional Scenario with land-based II and activity-based accounting approaches, the accounted carbon stock change is not consistent with the 2008-2012 actual changes in carbon stocks on land under Article 3.3, except in the case of short rotation cycles.

61. In neither of the two Definitional Scenarios is the accounted carbon stock change consistent with the 2008-2012 actual carbon stock changes, nor with the net exchanges with the atmosphere, at the national and global levels in part because the land under Article 3.3 is small in comparison with the national and global forest area. [3.3.2, 3.5.4]

\subsection{Additional Activities}

62. The magnitude of the stock changes from additional activities that might be included under Article 3.4 rests, inter alia, on any decisions that remain to be made in the process of implementing the Kyoto Protocol. A consideration of carbon stocks changes and net emissions of greenhouse gas emissions associated with additional activities on managed lands entails synthesizing available technical and scientific data, outlining the outcomes of one policy scenario, and assessing the aggregate impact of policies and other factors. The scientific literature to support such an analysis is currently quite limited. [4.3]

63. One such scenario is presented in Table 4, to illustrate in a general sense the potential scope for carbon stock increases through some broadly defined activities. It provides data and information on carbon stock changes for some candidate activities under Article 3.4 for the year 2010. This scenario relies on three components relating to the candidate activities: (1) an estimate of current relevant land areas (column 2); (2) an assumed percentage of those lands on which an activity would be applied in 2010 (column 3); and (3) a research-derived estimate of the annual rate of carbon stock increase per hectare (column 4). The uptake rate is multiplied by the applicable land area to approximately calculate the change in carbon stock in the year 2010 (column 5).
64. Table 4, rather than providing precise projections, reports calculated stock changes assuming an ambitious policy agenda that promotes the application of activities to a significantly greater share of the relevant land base than would have otherwise occurred. The assumed percentage of lands on which the activity is applied is derived from considered professional judgment based on existing literature of what a range of sustained and effective initiatives, which vary across countries, could achieve. The share of land on which the activity is actually applied in 2010 depends to a great extent on the accounting system under Article 3.4, the evolving economic and social aspects of the activity, and landowner response to incentives, among other factors. Thus, the total annual stock changes in Table 4 (column 5) are likely to be on the high side.

65. Table 4 estimates do not necessarily represent credits under Article 3.4 of the Kyoto Protocol, even if such levels of stock change are achieved, because the Protocol may include approaches that limit the applicability of these calculations.

66. Table 4 illustrates the estimated carbon stock changes from example additional activities within Annex I and globally, assuming roughly similar levels of policy support. For example, Table 4 suggests that although conversion of cropland to grassland can provide a relatively large carbon stock increase per hectare converted, forest management improvements, which can be applied over a larger land base, may provide relatively larger total annual increases. Very different estimates in changes of emissions and removals associated with options for additional land use, land-use change, and forestry activities would result from different definitions of additional activities that might be agreed under Article 3.4, different accounting approaches, and different decisions that might be taken on implementation rules for Article 3.4.

67. There is potential for carbon uptake into biomass, which may be stored over a time period of decades in wood products. Furthermore, biomass used for energy purposes, based on waste by-products of wood/crops or from trees/crops grown expressly for this purpose, has the potential to lead to a reduction in net greenhouse gas emissions by substituting for fossil fuels. [1.4.3, 1.4.4]

68. Table 4 does not account for the possibly significant non$\mathrm{CO}_{2}$ greenhouse gas emissions and removals that could be influenced by the candidate activities. For example, the rates do not reflect net emissions of $\mathrm{CH}_{4}$ or $\mathrm{N}_{2} \mathrm{O}$ from agricultural practices or wetlands/permafrost management. The table also does not include the carbon stock impact of the use of biofuels and the changing wood product pools, and consideration of forest management does not include avoided deforestation, which is dealt with in Table 3.

\section{Project-Based Activities}

69. A LULUCF project can be defined as a planned set of activities aimed at reducing greenhouse gas emissions or 
Table 4: Relative potential in 2010 for net change in carbon stocks through some improved management and changed land-use activities. ${ }^{a}$

\begin{tabular}{|c|c|c|c|c|}
\hline (1) Activity & $\begin{array}{l}\text { (2) Total } \\
\text { Areab }^{\mathbf{b}} \\
\text { (Mha) }\end{array}$ & $\begin{array}{l}\text { (3) Assumed } \\
\text { Percentage of Total } \\
\text { Area of Column } 2 \\
\text { under Activity } \\
\text { in } 2010(\%)\end{array}$ & $\begin{array}{l}\text { (4) Net Annual } \\
\text { Rate of Change } \\
\text { in Carbon Stocks } \\
\text { per Hectareb } \\
\left(\mathrm{t} \mathrm{C} \mathbf{~ h a}^{-1} \mathbf{y r}^{-1}\right)\end{array}$ & 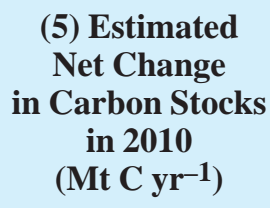 \\
\hline \multicolumn{5}{|l|}{ A. Annex I Countries } \\
\hline \multicolumn{5}{|l|}{ (a) Improved Management within a Land Usec } \\
\hline Forest Management & 1900 & 10 & 0.5 & 100 \\
\hline Cropland Management & 600 & 40 & 0.3 & 75 \\
\hline Grazing Land Management & 1300 & 10 & 0.5 & 70 \\
\hline Agroforestry & 83 & 30 & 0.5 & 12 \\
\hline Rice Paddies & 4 & 80 & 0.1 & $<1$ \\
\hline Urban Land Management & 50 & 5 & 0.3 & 1 \\
\hline \multicolumn{5}{|l|}{ (b) Land-Use Change } \\
\hline Conversion of Cropland to Grassland & 600 & 5 & 0.8 & 24 \\
\hline Agroforestry & $<1$ & 0 & 0 & 0 \\
\hline Wetland Restoration & 230 & 5 & 0.4 & 4 \\
\hline Restoring Severely Degraded Land & 12 & 5 & 0.25 & 1 \\
\hline
\end{tabular}

\section{B. Global Estimates}

(a) Improved Management within a Land Use

Forest Management

Cropland Management

Grazing Land Management

Agroforestry

Rice Paddies

Urban Land Management

(b) Land-Use Change

Agroforestry

Conversion of Cropland to Grassland

Wetland Restoration

Restoring Severely Degraded Land

$\begin{array}{rr}4050 & 10 \\ 1300 & 30 \\ 3400 & 10 \\ 400 & 20 \\ 150 & 50 \\ 100 & 5\end{array}$

10

30

0.4

170

0.3

0.7

0.3

0.1

0.3

125

240

20

50

$\begin{array}{rr}630 & 20 \\ 1500 & 3 \\ 230 & 5 \\ 280 & 5\end{array}$

$\begin{array}{lr}3.1 & 390 \\ 0.8 & 38 \\ 0.4 & 4 \\ 0.3 & 3\end{array}$

a Totals were not included in the table for several reasons: (i) The list of candidate activities is not exclusive or complete; (ii) it is unlikely that all countries would apply all candidate activities; and (iii) the analysis does not presume to reflect the final interpretations of Article 3.4. Some of these estimates reflect considerable uncertainty.

b A summary of reference sources is contained in Tables 4-1 and 4-4 of this Special Report. Calculated values were rounded to avoid the appearance of precision beyond the intent of the authors. The rates given are average rates that are assumed to remain constant to 2010 .

c Assumed to be the best available suite of management practices for each land use and climatic zone.

enhancing carbon stocks that is confined to one or more geographic locations in the same country and specified time period and institutional frameworks such as to allow net greenhouse gas emissions or enhancing carbon stocks to be monitored and verified. Experience is being gained in Activities Implemented Jointly (AIJ) and other LULUCF projects that are under initial stages of implementation in at least 19 countries.

70. Assessment of the experience of these projects is constrained by the small number, the limited range of project types, the uneven geographic distribution, the short period of field operations to date, and the absence of an internationally agreed set of guidelines and methods to establish baselines and quantify emissions and uptake. Generally, these projects do not report all greenhouse gas emissions or estimate leakage, and few have independent review.

71. However, through the experience of LULUCF projects aimed to mitigate climate change, it is possible in some cases to develop approaches to address some of the critical issues (see Table 5).

72. There are 10 projects aimed at decreasing emissions through avoiding deforestation and improving forest management, and 11 projects aimed at increasing the uptake of carbon mostly forest projects in tropical countries (see Table 5). [5.2.2] 
Table 5: Carbon uptakelestimated emissions avoided from carbon stocks, assuming no leakage outside the project boundaries, by selected AIJ Pilot Phase and other LULUCF projects, in some level of implementation. a,b,c,d,e

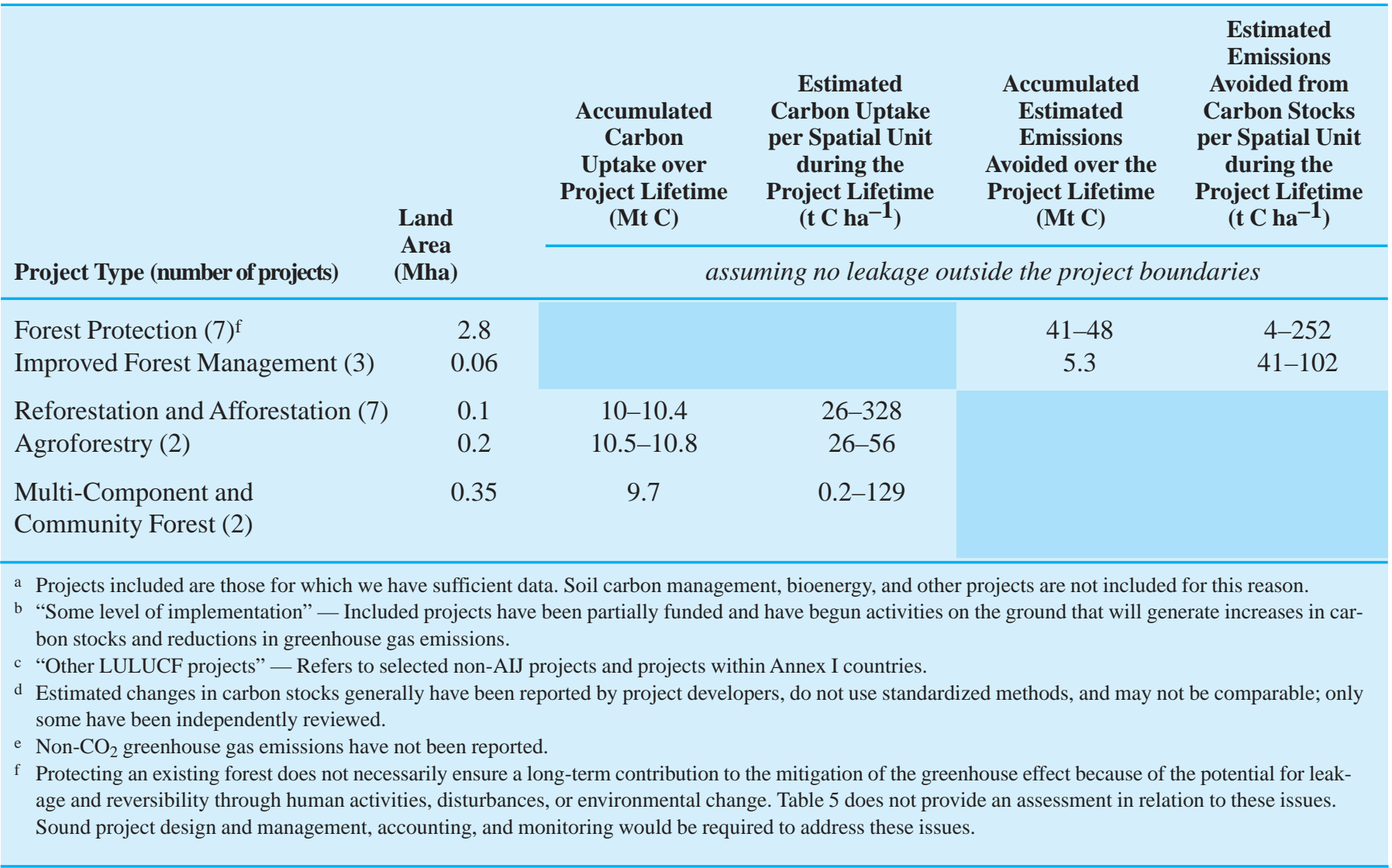

73. Methods of financial analysis among these projects have not been comparable. Moreover the cost calculations do not cover, in most instances, inter alia, costs for infrastructure, monitoring, data collection and interpretation costs, opportunity costs of land and maintenance, or other recurring costs, which are often excluded or overlooked. Recognizing the different methods used, the undiscounted cost and investment estimates range from US\$ $0.1-28$ per ton of carbon, simply dividing project cost by their total reported accumulated carbon uptake or estimated emissions avoided, assuming no leakage outside the project boundaries. [5.2.3]

74. Project-level financial analysis methods are widely used and fairly standardized in development assistance and private investment projects. But they have yet to be consistently applied to, and reported for, LULUCF projects aiming at mitigating climate change. Guidelines for developing methods of financial analysis may be needed in the future. [5.2.3]

75. LULUCF projects aiming to mitigate climate change may provide socioeconomic and environmental benefits primarily within project boundaries, although they may also pose risks of negative impacts. Experience from most of the pilot projects to date indicates that involvement of local stakeholders in the design and management of project activities is often critical. Other factors affecting the capacity of projects to increase carbon uptake and avoid greenhouse gas emissions and to have other benefits include consistency with national and/or international sustainable development goals, and institutional and technical capacity to develop and implement project guidelines and safeguards. $[2.5 .2,5.6]$

76. The accounting of changes in carbon stocks and net greenhouse gas emissions involve a determination that project activities lead to changes in carbon stocks and net greenhouse gas emissions that are additional to a without-project baseline. Currently there is no standard method for determining baselines and additionality. Approaches include determining project-specific baselines or generic benchmarks. Most AIJ projects have used a project-specific approach that has an advantage of using better knowledge of local conditions yielding more accurate prediction. A disadvantage is that project developers may choose scenarios that maximize their projected benefits. Baselines may be fixed throughout the duration of a project or periodically adjusted. Baseline adjustments would ensure more realistic estimates of changes in carbon uptake or greenhouse gas emissions but would create uncertainties for project developers. [5.3.2, Table 5-4]

77. Projects that reduce access to land, food, fiber, fuel, and timber resources without offering alternatives may result in carbon leakage as people find needed supplies elsewhere. A few pilot projects have been designed with the aim of reducing leakage by explicitly incorporating components 
that supply the resource needs of local communities (e.g., establishing fuelwood plantations to reduce pressures on other forests), and that provide socioeconomic benefits that create incentives to maintain the project. Due to leakage, the overall consideration of the climate change mitigation effects of a project may require assessments beyond the project boundary, as addressed in paragraph 49. [2.3, 5.3.3]

78. Project accounting and monitoring methods could be matched with project conditions to address leakage issues. If leakage is likely to be small, then the monitoring area can be set roughly equal to the project area. Conversely, where leakage is likely to be significant the monitoring area could be expanded beyond the project area, although this would be more difficult when the leakage occurs across national boundaries. Two possible approaches could then be used to estimate leakage. One would be to monitor key indicators of leakage, and the second would be to use standard risk coefficients developed for project type and region. In either case, leakage could be quantified and subsequently changes in carbon stock and greenhouse gas emissions attributed to the project could be reestimated. The effectiveness of these two approaches is untested. [5.3.3]

79. LULUCF projects raise a particular issue with respect to permanence (see paragraph 40). Different approaches have been proposed to address the duration of projects in relation to their ability to increase carbon stocks and decrease greenhouse gas emissions, inter alia: (i) They should be maintained in perpetuity because their "reversal" at any point in time could invalidate a project; and (ii) they should be maintained until they counteract the effect of an equivalent amount of greenhouse gases emitted to the atmosphere. [5.3.4]

80. Several approaches could be used to estimate the changes in carbon stocks and greenhouse gas emissions of LULUCF projects: (i) estimating carbon stocks and greenhouse gas emissions at a given point in time; (ii) estimating the average changes of carbon stocks or greenhouse gas emissions over time in a project area; or (iii) allowing for only a part of the total changes in carbon stocks or greenhouse gas emissions for each year that the project is maintained (e.g., tonne-year method). The year-to-year distribution of changes in carbon stocks and greenhouse gas emissions over the project duration varies according to the accounting method used. [5.4.2, Table 5-9]

81. LULUCF projects are subject to a variety of risks because of their exposure to natural and anthropogenic factors. Some of these risks particularly pertain to land-use activities (e.g., fires, extreme meteorological events, and pests for forests), while others are applicable to greenhouse gas mitigation projects in both LULUCF and energy sectors such as political and economic risks. Risk reduction could be addressed through a variety of approaches internal to the project, such as introduction of good practice management systems, diversification of project activities and funding sources, self-insurance reserves, involvement of local stakeholders, external auditing, and verification. External approaches for risk reduction include standard insurance services, regional carbon pools, and portfolio diversification. [5.3.5]

82. Techniques and tools exist to measure carbon stocks in project areas relatively precisely depending on the carbon pool. However, the same level of precision for the climate change mitigation effects of the project may not be achievable because of difficulties in establishing baselines and due to leakage. Currently, there are no guidelines as to the level of precision to which pools should be measured and monitored. Precision and cost of measuring and monitoring are related. Preliminary limited data on measured and monitored relevant aboveground and below-ground carbon pools to precision levels of about $10 \%$ of the mean at a cost of about US\$ $1-5$ per hectare and US\$ $0.10-0.50$ per ton of carbon have been reported. Qualified independent third-party verification could play an essential role in ensuring unbiased monitoring. [5.4.1, 5.4.4]

\section{Reporting Guidelines for the Relevant Articles of the Kyoto Protocol}

83. Under Article 5.2 of the Kyoto Protocol, the Revised 1996 Guidelines for National Greenhouse Gas Inventories provide the basis for the accounting and reporting of anthropogenic emissions by sources and removals by sinks of all greenhouse gases not controlled by the Montreal Protocol. These Guidelines were developed to estimate and report national greenhouse gas inventories under the United Nations Framework Convention on Climate Change (UNFCCC), not for the particular needs of the Kyoto Protocol. However, the Guidelines do provide a framework for addressing the accounting and reporting needs of the Kyoto Protocol. Elaboration of the Land-Use Change and Forestry Sector of the Guidelines may be needed, reflecting possible decisions by the Parties for accounting and reporting LULUCF under the Kyoto Protocol, taking into account, inter alia:

- Any decisions made by Parties on ARD under Article 3.3 and on additional activities under Article 3.4; [6.3.1, 6.3.2]

- The need to ensure transparency, completeness, consistency, comparability, accuracy, and verifiability; $[6.2 .2,6.2 .3,6.4 .1]$

- Consistent treatment of Land-Use Change and Forestry as other Sectors, with respect to uncertainty management and other aspects of good practice; [6.4.1]

- Any decisions adopted by Parties to address other accounting issues (e.g., permanence, the meaning of "human induced" and "direct human induced," wood products, and project based activities). [6.4.1] 


\section{Potential for Sustainable Development}

84. Consideration would need to be given to synergies and tradeoffs related to LULUCF activities under the UNFCCC and its Kyoto Protocol in the context of sustainable development including a broad range of environmental, social, and economic impacts, such as: (i) biodiversity; (ii) the quantity and quality of forests, grazing lands, soils, fisheries, and water resources; (iii) the ability to provide food, fiber, fuel, and shelter; and (iv) employment, human health, poverty, and equity. [2.5.1, 3.6]

85. For example, converting non-forest land to forest will typically increase the diversity of flora and fauna, except in situations where biologically diverse non-forest ecosystems, such as native grasslands, are replaced by forests consisting of single or a few species. Afforestation can also have highly varied impacts on groundwater supplies, river flows, and water quality. [3.6.1]

86. A system of criteria and indicators could be used to assess and compare sustainable development impacts across LULUCF alternatives. While there are no agreed upon set of criteria and indicators, several sets are being developed for closely related purposes, for example assessment of contributions to sustainable development by the United Nations Commission on Sustainable Development. [2.5.2]

87. For activities within countries or projects between countries, if sustainable development criteria vary significantly across countries or regions, there may be incentives to locate activities and projects in areas with less stringent environmental or socioeconomic criteria. [2.5.2]

88. Several sustainable development principles are incorporated in other multilateral environmental agreements, including the United Nations Convention on Biological Diversity, the United Nations Convention to Combat Desertification, and the Ramsar Convention on Wetlands. Consideration may be given to the development of synergies between LULUCF activities and projects that contribute to the mitigation or adaptation to climate change with the goals and the objectives of these and other relevant multilateral environmental agreements. [2.5.2]

89. Some of the more formal approaches to sustainable development assessment that could be applied at the project level are, for example, environmental and socioeconomic impact assessments. These methods have been applied across a wide range of countries and site-specific activities to date and could be modified to be applicable to LULUCF projects. $[2.5 .2 .2]$

90. Some critical factors affecting the sustainable development contributions of LULUCF activities and projects to mitigate and adapt to climate change include: institutional and technical capacity to develop and implement guidelines and procedures; extent and effectiveness of local community participation in development, implementation, and distribution of benefits; and transfer and adoption of technology. $[5.5,5.6]$ 


\section{Appendix I - Conversion Units}

$\begin{array}{llll}1 \text { tonne }(\mathrm{t}) & 1000 \text { kilogram }(\mathrm{kg}) & 10^{6} \mathrm{gram}(\mathrm{g}) & 1 \text { Megagram }(\mathrm{Mg}) \\ 1 \text { Megatonne }(\mathrm{Mt}) & 1000000 \mathrm{t} & 10^{12} \mathrm{~g} & 1 \text { 1Teragram }(\mathrm{Tg}) \\ 1 \text { Gigatonne }(\mathrm{Gt}) & 1000000000 \mathrm{t} & \\ 1 \text { hectare }(\mathrm{ha}) & 10000 \text { square metre }\left(\mathrm{m}^{2}\right) & \\ 1 \text { square kilometre }\left(\mathrm{km}^{2}\right) & 100 \text { hectare }(\text { ha) } & \\ 1 \text { tonne per hectare }\left(\mathrm{t} \mathrm{ha}^{-1}\right) & 100 \text { gram per square metre }\left(\mathrm{g} \mathrm{m}^{-2}\right) & \\ 1 \text { tonne carbon } & 3.67 \text { tonne carbon dioxide }\left(\mathrm{t} \mathrm{CO}_{2}\right) & \\ 1 \text { tonne carbon dioxide } & 0.273 \text { tonne carbon }(\mathrm{t} \mathrm{C)} & \\ 1 \text { tonne } & 0.984 \text { imperial ton } & \\ 1 \text { hectare (ha) } & 2.471 \text { acre } & \\ 1 \text { square kilometre }\left(\mathrm{km}^{2}\right) & 0.386 \text { square mile } & \\ 1 \text { tonne per hectare }\left(\mathrm{t} \mathrm{ha}^{-1}\right) & 892 \text { pound per acre } & \end{array}$




\title{
Appendix II — Relevant Portions of Kyoto Protocol Articles Discussed in this Special Report
}

\author{
[Concepts in bold are discussed in the SPM]
}

Article 2.1: Each Party included in Annex I in achieving its quantified emission limitation and reduction commitments under Article 3, in order to promote sustainable development, shall:

(a) Implement and/or further elaborate policies and measures in accordance with its national circumstances, such as:

(ii) Protection and enhancement of sinks and reservoirs of greenhouse gases not controlled by the Montreal Protocol, taking into account its commitments under relevant international environmental agreements; promotion of sustainable forest management practices, afforestation and reforestation;

(iii) Promotion of sustainable forms of agriculture in light of climate change considerations.

(b) Cooperate with other such Parties to enhance the individual and combined effectiveness of their policies and measures adopted under this Article, pursuant to Article 4, paragraph 2(e)(i), of the Convention. To this end, these Parties shall take steps to share their experience and exchange information on such policies and measures, including developing ways of improving their comparability, transparency, and effectiveness. The Conference of the Parties serving as the meeting of the parties to this Protocol shall, at its first session or as soon as practicable thereafter, consider ways to facilitate such cooperation, taking into account all relevant information.

Article 3.1: "The Parties included in Annex I shall, individually or jointly, ensure that their aggregate anthropogenic carbon dioxide equivalent emissions of greenhouse gases listed in Annex A do not exceed their assigned amounts, calculated pursuant to their quantified emission limitation and reduction commitments inscribed in Annex B and in accordance with the provisions of this Article, with a view to reducing their overall emissions of such gases by at least $5 \%$ below 1990 levels in the commitment period 2008-2012."

Article 3.3: The net changes in greenhouse gas emissions by sources and removals by sinks resulting from direct humaninduced land use change and forestry activities, limited to afforestation, reforestation and deforestation since 1990, measured as verifiable changes in carbon stocks in each commitment period, shall be used to meet the commitments under this Article of each Party included in Annex I. The greenhouse gas emissions by sources and removals by sinks associated with those activities shall be reported in a transparent and verifiable manner and reviewed in accordance with Articles 7 and 8.

Article 3.4: Prior to the first session of the COP serving as the meeting of the Parties to this Protocol, each Party included in Annex I shall provide, for consideration by the SBSTA, data to establish its level of carbon stocks in 1990 and to enable an estimate to be made of its changes in carbon stocks in subsequent years. The COP serving as the meeting of the Parties to this Protocol shall, at its first session or as soon as practicable thereafter, decide upon modalities, rules and guidelines as to how, and which, additional human-induced activities related to changes in greenhouse gas emissions by sources and removals by sinks in the agricultural soils and the land-use change and forestry categories shall be added to, or subtracted from, the assigned amounts for Parties included in Annex I, taking into account uncertainties, transparency in reporting, verifiability, the methodological work of the IPCC, the advice provided by the SBSTA in accordance with Article 5 and the decisions of the COP. Such a decision shall apply in the second and subsequent commitment periods. A Party may choose to apply such a decision on these additional human-induced activities for its first commitment period, provided that these activities have taken place since 1990.

Article 3.7: In the first quantified emission limitation and reduction commitment period, from 2008 to 2012, the assigned amount for each Party included in Annex I shall be equal to the percentage inscribed for it in Annex $B$ of its aggregate anthropogenic carbon dioxide equivalent emissions of the greenhouse gases listed in Annex A in 1990, or the base year or period determined in accordance with paragraph 5 above, multiplied by five. Those Parties included in Annex I for whom land use change and forestry constituted a net source of greenhouse gas emissions in 1990, shall include in their 1990 emissions base year or period, the aggregate anthropogenic carbon dioxide equivalent emissions minus removals in 1990 from land use change for the purposes of calculating their assigned amount.

Article 5.2: Methodologies for estimating anthropogenic emissions by sources and removals by sinks of all greenhouse gases not controlled by the Montreal Protocol shall be those accepted by the Intergovernmental Panel on Climate Change and agreed upon by the Conference of the Parties at its third session. Where such methodologies are not used, appropriate adjustments shall be applied according to methodologies agreed upon by the Conference of the Parties serving as the meeting of the Parties to this protocol at its first session. Based on the work of, inter alia, the Intergovernmental Panel on Climate Change and advice 
provided by the Subsidiary Body for Science and Technological Advice, the Conference of the Parties serving as the meeting of the parties to this Protocol shall regularly review and, as appropriate, revise such methodologies and adjustments, taking into account any relevant decisions by the Conference of the Parties. Any revision to methodologies or adjustments shall be used only for the purposes of ascertaining compliance with commitments under Article 3 in respect of any commitment period adopted subsequent to that revision.

Article 6.1: For the purpose of meeting its commitments under Article 3, any Party included in Annex I may transfer to, or acquire from, any other such Party emission reduction units resulting from projects aimed at reducing anthropogenic emissions by sources or enhancing anthropogenic removals by sinks of greenhouse gases in any sector of the economy, provided that:

Article 6.1(b): Any such project provides a reduction in emissions by sources, or an enhancement of removals by sinks, that is additional to any that would otherwise occur.

Article 12.2: The purpose of the clean development mechanism shall be to assist Parties not included in Annex I in achieving sustainable development and in contributing to the ultimate objective of the Convention, and to assist Parties included in Annex I in achieving compliance with their quantified emission limitation and reduction commitments under Article 3.

Article 12.3(a): Parties not included in Annex I will benefit from project activities resulting in certified emissions reductions.

Article 12.3(b): Parties included in Annex I may use the certified emissions reductions accruing from such project activities to contribute to compliance with part of their quantified emission limitation and reduction commitments under Article 3, as determined by the Conference of the Parties serving as the meeting of the Parties to the Protocol.

Article 12.5: Emissions reductions resulting from each project activity shall be certified by operational entities to be designated by the COP serving as the meeting of the Parties to this Protocol, on the basis of:

Article 12.5(b): Real, measurable, and long-term benefits related to the mitigation of climate change.

Article 12.5(c): Reductions in emissions that are additional to any that would occur in the absence of the certified project. 


\section{Appendix III — Glossary}

\section{[These definitions are provided solely for the purpose of this Special Report]}

\section{Accuracy}

The degree to which the mean of a sample approaches the true mean of the population; lack of bias.

\section{Activity}

A practice or ensemble of practices that take place on a delineated area over a given period of time.

\section{Baseline}

A reference scenario against which a change in greenhouse gas emissions or removals is measured.

\section{Bias}

Systematic over- or under-estimation of a quantity.

\section{Biosphere}

That component of the Earth system that contains life in its various forms, which includes its living organisms and derived organic matter (e.g., litter, detritus, soil).

\section{Carbon Flux}

Transfer of carbon from one carbon pool to another in units of measurement of mass per unit area and time (e.g., $\left.\mathrm{tC} \mathrm{ha}^{-1} \mathrm{y}^{-1}\right)$.

\section{Carbon Pool}

A reservoir. A system which has the capacity to accumulate or release carbon. Examples of carbon pools are forest biomass, wood products, soils, and atmosphere. The units are mass (e.g., t C).

\section{Carbon Stock}

The absolute quantity of carbon held within a pool at a specified time.

Flux

See "Carbon Flux."

\section{Forest Estate}

A forested landscape consisting of multiple stands of trees.

\section{Forest Stand}

A community of trees, including aboveground and belowground biomass and soils, sufficiently uniform in species composition, age, arrangement, and condition to be managed as a unit.

\section{Heterotrophic Respiration}

The release of carbon dioxide from decomposition of organic matter.

\section{Land Cover}

The observed physical and biological cover of the Earth's land as vegetation or man-made features.

\section{Land Use}

The total of arrangements, activities, and inputs undertaken in a certain land cover type (a set of human actions). The social and economic purposes for which land is managed (e.g., grazing, timber extraction, conservation).

\section{Permanence}

The longevity of a carbon pool and the stability of its stocks, given the management and disturbance environment in which it occurs.

Pool

See "Carbon Pool."

\section{Practice}

An action or set of actions that affect the land, the stocks of pools associated with it or otherwise affect the exchange of greenhouse gases with the atmosphere.

\section{Precision}

The repeatability of a measurement (e.g., the standard error of the sample mean).

\section{Regeneration}

The renewal of a stand of trees through either natural means (seeded on-site or adjacent stands or deposited by wind, birds, or animals) or artificial means (by planting seedlings or direct seeding)

Reservoir

A pool.

\section{Sequestration}

The process of increasing the carbon content of a carbon pool other than the atmosphere.

\section{Shifting Agriculture}

A form of forest use common in tropic forests where an area of forest is cleared, or partially cleared, and used for cropping for a few years until the forest regenerates. Also known as "slash and burn agriculture," "moving agriculture," or "swidden agriculture."

\section{Sink}

Any process or mechanism which removes a greenhouse gas, an aerosol, or a precursor of a greenhouse gas from the atmosphere. A given pool (reservoir) can be a sink for atmospheric 
carbon if, during a given time interval, more carbon is flowing into it than is flowing out.

\section{Source}

Opposite of sink. A carbon pool (reservoir) can be a source of carbon to the atmosphere if less carbon is flowing into it than is flowing out of it.

Stand

See "Forest Stand."

Stock

See "Carbon Stock."
Soil Carbon Pool

Used here to refer to the relevant carbon in the soil. It includes various forms of soil organic carbon (humus) and inorganic soil carbon and charcoal. It excludes soil biomass (e.g., roots, bulbs, etc.) as well as the soil fauna (animals).

\section{Uptake}

The addition of carbon to a pool. A similar term is "sequestration."

Wood Products

Products derived from the harvested wood from a forest, including fuelwood and logs and the products derived from them such as sawn timber, plywood, wood pulp, paper, etc. 


\section{LIST OF IPCC OUTPUTS}

(unless otherwise stated, all IPCC outputs are in English)

\section{IPCC FIRST ASSESSMENT REPORT, 1990}

a) CLIMATE CHANGE - The IPCC Scientific Assessment. The 1990 report of the IPCC Scientific Assessment Working Group (also in Chinese, French, Russian and Spanish).

b) CLIMATE CHANGE - The IPCC Impacts Assessment. The 1990 report of the IPCC Impacts Assessment Working Group (also in Chinese, French, Russian and Spanish).

c) CLIMATE CHANGE - The IPCC Response Strategies. The 1990 report of the IPCC Response Strategies Working Group (also in Chinese, French, Russian and Spanish).

d) Overview and Policymaker Summaries, 1990.

Emissions Scenarios (prepared by the IPCC Response Strategies Working Group), 1990.

Assessment of the Vulnerability of Coastal Areas to Sea Level Rise -A Common Methodology, 1991.

\section{IPCC SUPPLEMENT, 1992}

a) CLIMATE CHANGE 1992 - The Supplementary Report to the IPCC Scientific Assessment. The 1992 report of the IPCC Scientific Assessment Working Group.

b) CLIMATE CHANGE 1992 - The Supplementary Report to the IPCC Impacts Assessment. The 1992 report of the IPCC Impacts Assessment Working Group.

CLIMATE CHANGE: The IPCC 1990 and 1992 Assessments IPCC First Assessment Report Overview and Policymaker Summaries, and 1992 IPCC Supplement (also in Chinese, French, Russian and Spanish).

Global Climate Change and the Rising Challenge of the Sea. Coastal Zone Management Subgroup of the IPCC Response Strategies Working Group, 1992.

Report of the IPCC Country Study Workshop, 1992.

Preliminary Guidelines for Assessing Impacts of Climate Change, 1992

\section{IPCC SPECIAL REPORT, 1994}

CLIMATE CHANGE 1994 - Radiative Forcing of Climate Change and An Evaluation of the IPCC IS92 Emission Scenarios.

\section{IPCC SECOND ASSESSMENT REPORT, 1995}

a) CLIMATE CHANGE 1995 - The Science of Climate Change (including Summary for Policymakers). Report of IPCC Working Group I, 1995.

b) CLIMATE CHANGE 1995 - Scientific-Technical Analyses of Impacts, Adaptations and Mitigation of Climate Change (including Summary for Policymakers). Report of IPCC Working Group II, 1995.

c) CLIMATE CHANGE 1995 - The Economic and Social Dimensions of Climate Change (including Summary for Policymakers). Report of IPCC Working Group III, 1995.

d) The IPCC Second Assessment Synthesis of Scientific-Technical Information Relevant to Interpreting Article 2 of the UN Framework Convention on Climate Change, 1995.

(The IPCC Synthesis and the three Summaries for Policymakers have been published in a single volume and are also available in Arabic, Chinese, French, Russian and Spanish.)

\section{IPCC METHODOLOGIES}

a) IPCC Guidelines for National Greenhouse Gas Inventories (3 volumes), 1994 (also in French, Russian and Spanish).

b) IPCC Technical Guidelines for Assessing Climate Change Impacts and Adaptations, 1995 (also in Arabic, Chinese, French, Russian and Spanish).

c) Revised 1996 IPCC Guidelines for National Greenhouse Gas Inventories (3 volumes), 1996.

d) Good Practice Guidance and Uncertainty Management in National Greenhouse Gas Inventories, IPCC Task Force on National Greenhouse Gas Inventories, 2000.

\section{IPCC TECHNICAL PAPERS}

TECHNOLOGIES, POLICIES AND MEASURES FOR MITIGATING CLIMATE CHANGE — IPCC Technical Paper 1, 1996 (also in French and Spanish).

AN INTRODUCTION TO SIMPLE CLIMATE MODELS USED IN THE IPCC SECOND ASSESSMENT REPORT - IPCC Technical Paper 2, 1997 (also in French and Spanish).

STABILIZATION OF ATMOSPHERIC GREENHOUSE GASES: PHYSICAL, BIOLOGICAL AND SOCIO-ECONOMIC IMPLICATIONS — IPCC Technical Paper 3, 1997 (also in French and Spanish).

IMPLICATIONS OF PROPOSED $\mathrm{CO}_{2}$ EMISSIONS LIMITATIONS - IPCC Technical Paper 4, 1997 (also in French and Spanish).

\section{IPCC SPECIAL REPORTS}

THE REGIONAL IMPACTS OF CLIMATE CHANGE: AN ASSESSMENT OF VULNERABILITY (including Summary for Policymakers, which is available in Arabic, Chinese, English, French, Russian and Spanish).

A Special Report of IPCC Working Group II, 1997. 
AVIATION AND THE GLOBAL ATMOSPHERE (including Summary for Policymakers, which is available in Arabic, Chinese, English, French, Russian and Spanish).

A Special Report of IPCC Working Groups I and III, 1999.

METHODOLOGICAL AND TECHNOLOGICAL ISSUES IN TECHNOLOGY TRANSFER (including Summary for Policymakers, which is available in Arabic, Chinese, English, French, Russian and Spanish).

A Special Report of IPCC Working Group III, 2000.
EMISSIONS SCENARIOS (including Summary for Policymakers, which is available in Arabic, Chinese, English, French, Russian and Spanish).

A Special Report of IPCC Working Group III, 2000.

LAND USE, LAND-USE CHANGE, AND FORESTRY (including Summary for Policymakers, which is available in Arabic, Chinese, English, French, Russian and Spanish).

A Special Report of the IPCC, 2000. 
